\title{
The contribution of the NEMO-SN1 seafloor observatory to improve the seismic locations in the Ionian Sea (Italy)
}

\author{
Tiziana Sgroi ${ }^{*}, 1$, Graziella Barberi ${ }^{2}$, Alessandro Marchetti ${ }^{3}$ \\ (1) Istituto Nazionale di Geofisica e Vulcanologia, Sezione Roma2, Roma, Italy \\ (2) Istituto Nazionale di Geofisica e Vulcanologia, Osservatorio Etneo, Catania, Italy \\ (3) Istituto Nazionale di Geofisica e Vulcanologia, Osservatorio Nazionale Terremoti, Roma, Italy
}

Article history: received September 16, 2020; accepted July 5, 2021

\begin{abstract}
The Western Ionian Sea is characterised by an active and diffuse seismicity, directly related to the convergence of the European and African Plates and by gravitational sinking and rollback of the oceanic lithosphere. In this area, the location of earthquakes is characterised by considerable uncertainties due to large azimuthal gaps, resulting in notable location errors. This problem was partially overcome with the use of data recorded by NEMO-SN1 seafloor observatory (October 2002 February 2003; June 2012 - May 2013). We relocated 1130 crustal and sub-crustal earthquakes using land network and NEMO-SN1 data. As most events occurred on Mt. Etna, we focused on 358 earthquakes in the offshore area and near the coasts of Sicily and Calabria. The use of the combined land-marine networks has improved the earthquake locations in terms of azimuthal GAP, as well as in horizontal and vertical errors. The comparison between locations performed with and without NEMO-SN1 data shows that differences in latitude, longitude and depths are more evident in the Western Ionian Sea and in the coast of Sicily, where values of the differences over $5 \mathrm{~km}$ correspond to structural heterogeneities. The increased number of seismic stations deployed on land from 2003 to 2012 did not influence the location of events occurring offshore, where NEMO-SN1 continued to be the distinctive tool in the location process. Moreover, the new 73 focal mechanisms computed with P-wave polarities from NEMO-SN1 and land stations are in agreement with the regional structural model, showing a prevalent normal, normal/oblique, and strike-slip kinematics. The similarity of two new focal solutions with the mechanisms of the main shock and aftershock of the 1990 earthquake demonstrates that the seismic structures are still active and potentially dangerous. The P-wave travel time residual analysis confirms the activity along the main structural alignments. A single point of observation in the Ionian Sea can significantly improve the quality of locations, giving an opportunity to focus on the seismogenic structures responsible for the occurrence of medium-to-high magnitude earthquakes.
\end{abstract}

Keywords: Earthquake location; Focal mechanisms; Tectonic and volcanic structures; NEMO-SN1 seafloor observatory; Ionian Sea. 


\section{Tiziana Sgroi et al.}

\section{Introduction}

The location of seismic events in the offshore areas is uncertain using only land-based seismic networks due to the large azimuthal gaps. In the last few decades, Ocean Bottom Seismometers (OBSs) and seafloor observatories have been used to improve the reliability of earthquake locations in the offshore or near the coasts. Numerous experiments have been performed with this purpose using OBSs stations [Dahm et al., 2002; Barberi et al., 2006; Sgroi et al., 2006] and seafloor observatories [Sgroi et al., 2007; Tréhu et al., 2018], demonstrating shifts of several km in the hypocentre determination [Lawton et al., 1982; Hino et al., 1996; Sgroi et al., 2006]. Moreover, OBS networks are frequently used to locate offshore microseismicity of tectonic and volcanic origin, recorded poorly or not at all on-land [Shinohara et al. 2003; Tilmann et al. 2004; Goslin et al. 2005; Sgroi et al. 2006; 2007; Wilcock et al., 2016].

In Italy, the difficulty in precisely locating the offshore seismicity by land-based seismic networks prevalently concerns earthquakes occurring in marine areas, such as the Ionian Sea, one of the most seismically active areas in the Central Mediterranean. In this region, the highest magnitude earthquakes ever measured in Italy during historical and recent times occurred [1169, $\mathrm{M}_{\mathrm{w}}$ 6.6; 1693, $\mathrm{M}_{\mathrm{w}}$ 7.4; 1908, $\mathrm{M}_{\mathrm{w}} 7.2 ; 1990, \mathrm{M}_{\mathrm{w}}$ 5.7; Boschi et al., 1997], often followed by severe tsunamis [Tinti et al., 2004)] Despite many studies in the Ionian Sea recognising the offshore seismogenic structures [Bianca et al., 1999; Gutscher et al., 2016], their locations are questionable or entirely unknown.

These problems were overcome thanks to the deployment of the NEMO-SN1 seafloor observatory in the Ionian Sea, about $25 \mathrm{~km}$ offshore eastern Sicily, as a node of the EMSO ERIC European Multidisciplinary Seafloor and water-column Observatory European Research Infrastructure Consortium (www.emso.eu) [Favali et al., 2006; Favali and Beranzoli, 2009]. In the Ionian Sea, many other experiments using OBSs have been performed [Coltelli et al., 2016; Billi et al., 2020] with the aim of focusing both on the volcanic and tectonic setting associated with the Mt. Etna volcano and the active faults in the Ionian basin.

In this work, we analysed the crustal and sub-crustal earthquakes recorded by NEMO-SN1 and by land stations during two periods (October 2002 - February 2003; June 2012 - May 2013). Notwithstanding the denser station coverage deployed on land from 2005 , the seafloor observatory proved to be a unique tool in improving the locations of earthquakes occurring at the sea. The integration of travel times significantly improved the earthquake locations, demonstrating how a single offshore station, strategically located, can contribute greatly towards focusing on the most dangerous active offshore seismic structures.

\section{Geological setting}

The NEMO-SN1 site in the Ionian Sea was chosen for its high seismic and volcanic hazards, related both to the seismogenic structures, sources of historical high-magnitude earthquakes, and Mt. Etna. The study area is characterised mainly by convergence of the European and African Plates and by gravitational sinking and rollback of oceanic lithosphere [e.g. Argnani, 2009].

From a structural viewpoint, the Malta Escarpment (ME in Figure 1) is a more than 150-km-long regional fault system, mostly submerged, that trends NNW-SSE and separates the subduction foreland basin from the oceanic crust [Scandone et al., 1981; Ben-Avraham et al., 1995; Hirn et al., 1997; Bianca et al., 1999; Meletti et al., 2000]. Two oppositely dipping fault systems, the Ionian Fault (IF in Figure 1) and the Alfeo-Etna Fault (AEF in Figure 1), have recently been described based on the analysis of multiscale geophysical data, which show deformations along prevailing NW-SE strike-slip/transtensional structures [Polonia et al., 2011; 2016]. The lengths of IF and AEF range from tens to hundreds of $\mathrm{km}$, therefore these structures are likely candidates as seismogenic sources of the highest magnitude earthquakes [Billi et al., 2010; Polonia et al., 2013; Gutscher et al., 2016]. The same structures may also be considered possible sources of significant micro-seismicity, which is not accurately detected by the land network [Sgroi et al., 2007].

In this complex picture, the origin and the anomalous position of Mt. Etna within the geodynamic context of the area are still controversial [e.g. Doglioni et al., 2001]. During the first deployment of NEMO-SN1 seafloor observatory, a vigorous explosive eruption occurred on Mt. Etna. The eruption started on October 26, 2002, two hours after the occurrence of a seismic crisis [Patanè, 2002; Barberi et al., 2004]. NEMO-SN1 proved an efficient tool also in the volcano-tectonic earthquakes monitoring, recording several dozens of earthquakes associated to the 
seismic crisis that were not well-recorded and located by the land seismic network on the volcano edifice [Sgroi et al., 2007]. Moreover, the detection capability of the seafloor observatory also enabled recording the low-frequency signal (volcanic tremor) that accompanied the 2002-2003 Mt. Etna eruption [Sgroi et al., 2019].

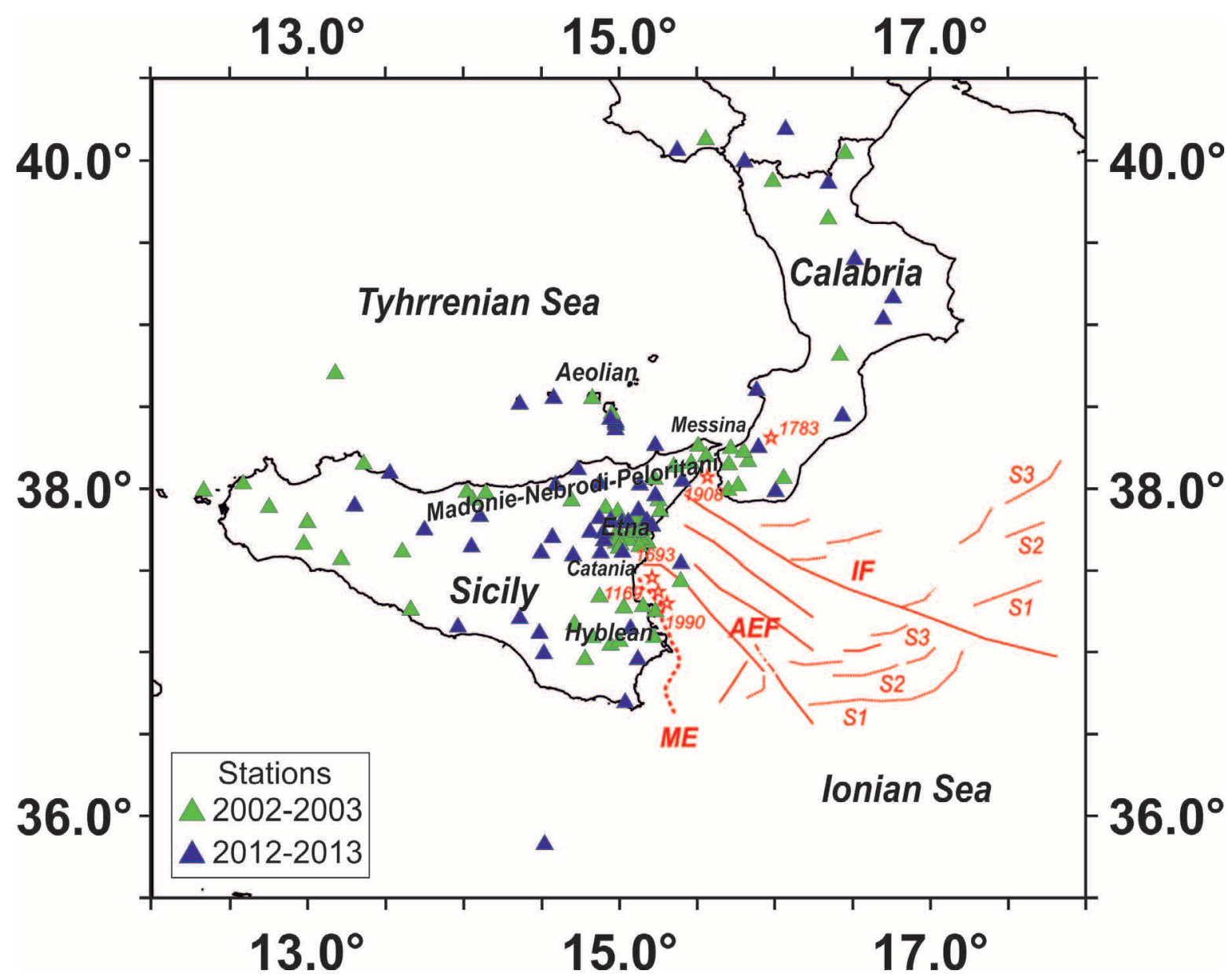

Figure 1. Map of seismic stations belonging to the Italian Seismic Network (Rete Sismica Nazionale, RSN) and Etna Regional Network (ERN), and the NEMO-SN1 seafloor observatory. The two colours indicate the operative seismic stations during the two periods of deployment of NEMO-SN1 (green triangles: October 2002 - February 2003; blue triangles: June 2012 - May 2013). The short-period stations deployed on land during the 2002-2003 period (green triangles) were replaced with enlarged and/or broad-band stations in 2005, while in the period 2012-2013 additional broad-band stations (blue triangles) increased the station coverage exclusively on land, without any improvement in earthquake detection capabilities of the RNS and ERN in the offshore. Main geological features including Malta escarpment (ME), Alfeo-Etna Fault and Ionian Fault [AEF and IF; Polonia et al., 2016], and splay faults (S1, S2, S3) are sketched in red. The epicentres of the five highest magnitude earthquakes recorded in the study area [1169, Mw 6.6; 1693, Mw 7.3; 1783 Mw 7.1; 1908, Mw 7.2; 1990, Mw 5.6; Boschi et al., 1997] are indicated with red stars and years.

\section{The NEMO-SN1 seafloor observatory and the land networks}

In the two periods, October 2002 - February 2003 and June 2012 - May 2013, the NEMO-SN1 seafloor observatory was deployed about $25 \mathrm{~km}$ offshore eastern Sicily, at a depth of $2100 \mathrm{~m}$ (Figure 1), as a node of EMSO, the European research infrastructure for seafloor and water column monitoring (www.emso.eu). The deployment 


\section{Tiziana Sgroi et al.}

site was chosen due to the importance of the Western Ionian Sea area in the long-term monitoring of environmental processes related to marine ecosystems, climate change, and geohazards. The seafloor observatory was equipped with a set of geophysical and oceanographic instruments (gravitymeter, hydrophone, Conductivity and Temperature versus Depth - CTD, 3-C single-point current meter, several status sensors), including a 3component broadband Guralp CMG-1T seismometer, with a 0.0027 to $50 \mathrm{~Hz}$ bandwidth frequency response and $100 \mathrm{~Hz}$ sampling rate. It was synchronized by a high-precision Rb clock, with a drift of less than $0.4 \mathrm{~ms} /$ day [Favali and Beranzoli, 2006; Favali et al., 2013; Sgroi et al., 2014]; these errors were well below the accuracy needed for the analysis performed in this work.

The NEMO-SN1 seafloor observatory was deployed in autonomous acoustic-linked mode at $37.442 \mathrm{~N}, 15.393 \mathrm{E}$, and $2072 \mathrm{~m}$ water depth [October 2002 - February 2003; Favali and Beranzoli, 2006; Favali et al., 2006; Sgroi et al., 2007] and in cabled mode at 37.548 N, $15.398 \mathrm{E}$ and $2037 \mathrm{~m}$ water depth [June 2012 - May 2013; Favali et al., 2010; 2013; Sgroi et al., 2014; Favali et al., 2015]. The metadata can be retrieved at the link http://www.moist.it/sites/western_ionian_sea/2

During the two periods, NEMO-SN1 recorded a great variety of seismic events, comprising teleseismic, regional and local events. Moreover, low-frequency signals, such as volcanic tremor and oceanographic noise, were recorded well, giving important insights into the dynamics of Mt. Etna volcano and the Ionian seafloor [Sgroi et al., 2019].

In this work, we collected data related to crustal and subcrustal earthquakes recorded by land stations of the Italian Seismic Network (Rete Sismica Nazionale, RSN) and the Etna Regional Network (ERN), both managed by the Istituto Nazionale di Geofisica e Vulcanologia (INGV - INGV Seismological Data Centre and Osservatorio Etneo) during the two deployments of NEMO-SN1 (Figure 1). In 2002-2003, the RSN comprised about 25 stations in the study area (green triangles in Figure 1), equipped with S-13 Teledyne Geotech seismometers, acquiring continuous data at $50-\mathrm{Hz}$ sampling rate. In the same years, the Etna Regional Network (ERN), mainly employed for the monitoring of Mt. Etna seismo-volcanic activity, was made up of about 20 stations distributed around the volcanic edifice (green triangles around the Mt. Etna area in Figure 1). Data were recorded by 3-component stations (Mark L4C) with a $160-\mathrm{Hz}$ sampling rate. Since 2005, a denser station coverage was achieved on land with the deployment of new broad-band seismic stations, while enlarged band sensors replaced the short-period ones in Sicily and in the area of Mt. Etna. In 2012-2013, the two land networks had approximately 150 stations in Sicily, Aeolian Islands, and southern Calabria (the additional stations are shown with blue triangles in Figure 1). These stations are equipped with 3-component extended band (Lennartz 5 s) and/or broad-band (Trillium 40 s) sensors [Amato and Mele, 2008; Schorlemmer et al., 2010].

\section{Data analyses}

\subsection{Land and marine data}

We gathered information on earthquake locations reported by the Italian Seismicity Catalogue [Catalogo della Sismicità Italiana, CSI; Castello et al., 2006], the Italian Seismic Bulletin [Bollettino Sismico Italiano, BSI; ISIDe Working Group, 2007] and the "Catalogo dei Terremoti della Sicilia Orientale - Calabria Meridionale, INGV, Catania" [Gruppo Analisi Dati Sismici, 2019], compiling a seismological dataset of 1130 crustal and sub-crustal earthquakes during the time-period covered by the NEMO-SN1 monitoring. We then analysed the waveforms and handpicked the arrival times of the events recorded both by land stations and NEMO-SN1. To standardize the compiled dataset in terms of location procedure and quality, we performed a relocation of all events, integrating arrival times both from land seismic stations and NEMO-SN1. Locations were performed using the Hypoellipse code [Lahr, 1989] which allows applying different 1D velocity models [Sgroi et al., 2012] and takes into account the negative elevation of the NEMOSN1 seafloor observatory [Sgroi et al., 2007; 2012]. In the 1D location process, seven available P-wave velocity models for the offshore-onshore south Calabria and Sicily are taken into account, being representative of the structural heterogeneity of the areas where seismic stations are placed. Starting from the southern Tyrrhenian Sea, the model of Monna et al. [2013], derived from a tomographic study performed around the Aeolian Islands, shows a crustal thickness of $\sim 23 \mathrm{~km}$; the model of Langer et al. [2007] represents the structural heterogeneity of the MadonieNebrodi-Peloritani system (Moho placed at $35 \mathrm{~km}$ ); the model of Hirn et al. [1991] is representative of Mt. Etna volcano and assumes a Moho depth of $30 \mathrm{~km}$; the models of Musumeci et al. [2003] and Sgroi et al. [2012] are indicative of geology and structures in the area of Hyblean plateau (crustal thickness of $28 \mathrm{~km}$ ) and central Sicily (Moho depth 
of $37 \mathrm{~km}$ ), respectively. For the Western Ionian Sea, a recent 1D velocity model [Sgroi et al., 2021] computed using data of NEMO-SN1 and characterized by a crustal thickness of $21 \mathrm{~km}$, was used in the $1 \mathrm{D}$ location process.

The integrated locations of the 1130 earthquakes are shown in Figure 2, where the two different colours indicate the earthquakes occurring in the two periods 2002-2003 (green circles) and 2012-2013 (blue circles), respectively.

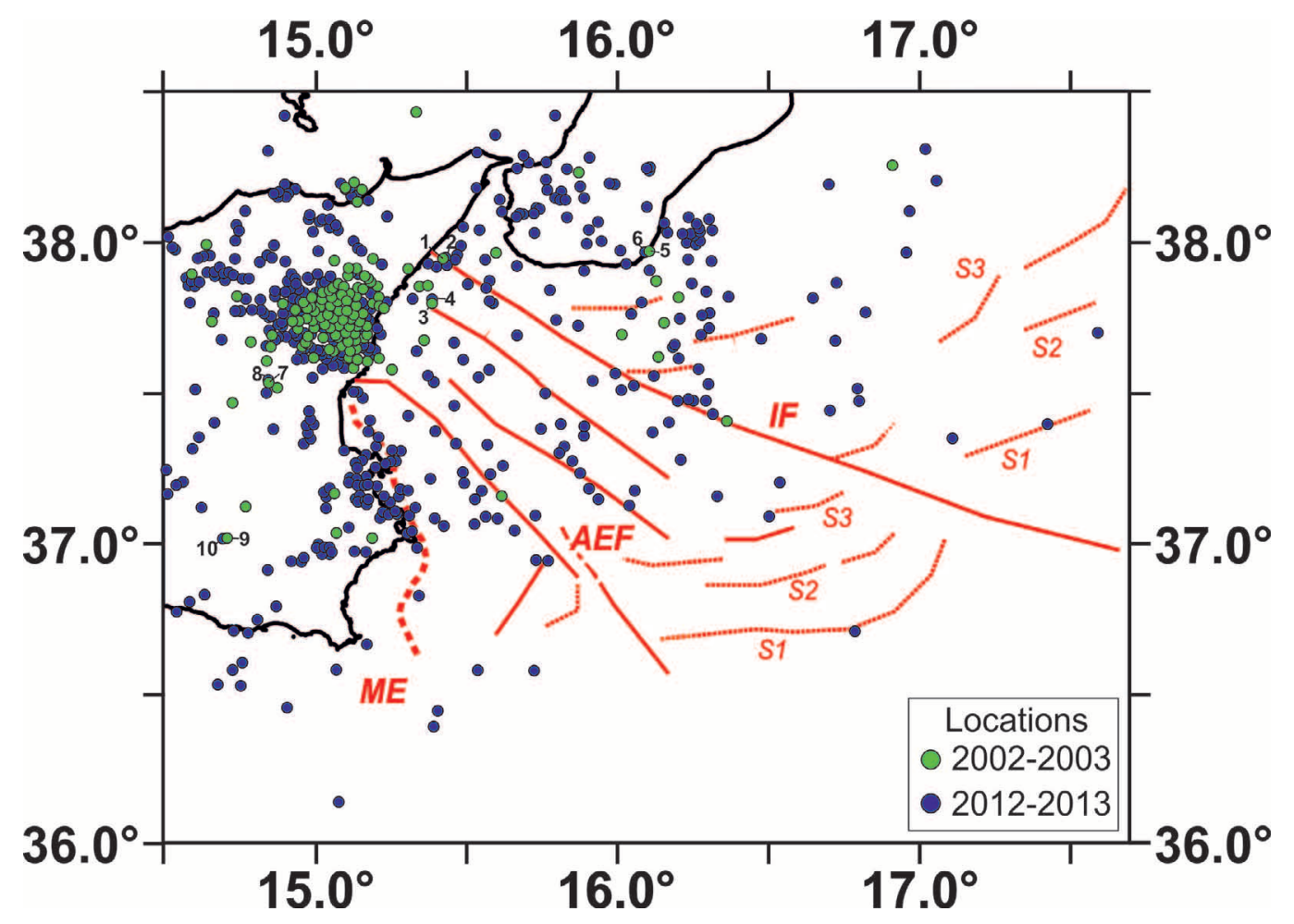

Figure 2. Map of seismicity recorded by NEMO-SN1 during the two deployment periods of the seafloor observatory: October 2002 - February 2003 (green circles) and June 2012 - May 2013 (blue circles). A total of 1130 locations were computed integrating the travel times of the land stations (RSN and ERN) and NEMO-SN1. Most earthquakes occurring in the period 2002-2003 are associated with the seismic swarm that preceded and accompanied the Mt. Etna eruption; in the period 2012-2013, although a high number of events took place on Mt. Etna, the seismicity occurred prevalently in the Ionian Sea and in the coastal area of south Calabria and eastern Sicily. The numbers from 1 to 10 indicate couples of events having similar locations and occurred in 2002-2003 and 2012-2013 (odd and even numbers, respectively); locations of these ten events are shown in Table 1. Main tectonic structures including Malta escarpment (ME), Alfeo-Etna Fault and Ionian Fault [AEF and IF; Polonia et al., 2016] and splay faults (S1, S2, S3) are sketched in red.

The distribution of locations is non-homogeneous as the cluster with the major concentration of earthquakes is associated with Mt. Etna, and is linked to its volcanic activity. About two weeks after the first NEMO-SN1 deployment (2002-2003), a vigorous explosive eruption occurred on Mt. Etna. Starting in the late hours of October 26,2002 , the eruption was preceded by a seismic swarm comprising several hundreds of earthquakes; most of them were recorded well by NEMO-SN1. A minor cluster of earthquakes is related to seismicity occurring in the transition onshore/offshore area of the Hyblean plateau and in correspondence of Messina Strait, while a minor and dispersed seismicity occurs at the external part of the Calabrian Arc in the Ionian Sea. Figure 2 shows that most seismicity during the 2002-2003 period was associated with the Mt. Etna eruption (with only a few events occurring offshore), while in the period 2012-2013 the volcano-tectonic seismicity associated with Mt. Etna was lower and earthquakes occurred prevalently in the offshore area. 


\section{Tiziana Sgroi et al.}

To focus on the influence of the increasing number of land seismic stations on location improvement during the two periods of deployment of NEMO-SN1, we compared five couples of earthquakes occurring alternatively in 20022003 and 2012-2013 (circles numbered in Figure 2) and having similar epicentres (all located with the use of travel times from NEMO-SN1; location parameters are listed in Table 1). The comparison of these events shows that locations are very similar for couples of earthquakes occurring offshore or near the coast (events 1-2, 3-4 and 5-6 in Figure 2; Table 1) with differences that are ascribable to the magnitude of events (a consistent difference in hypocentre depths is visible only for the couple of events 5-6). The azimuthal gaps show similar values, with a maximum difference of $9^{\circ}$ for the events $3-4$, and also horizontal and vertical errors are comparable. On the other hand, the two couples of events in central Sicily (events 7-8 and 9-10 in Figure 2; Table 1) are characterized by similar locations, while remarkable differences of the azimuthal gap ( $180^{\circ}$ for events $7-8$ and $147^{\circ}$ for events 9-10) are computed. These results indicate that the increasing seismic stations coverage has significantly improved the location of earthquakes occurring on land, without any influence in the offshore where NEMO-SN1 continued to be the distinctive tool in the location process.

\begin{tabular}{|c|c|c|c|c|c|c|c|c|c|c|c|c|}
\hline ID & $\begin{array}{c}\text { Date } \\
\text { (dd/mm/yyyy) }\end{array}$ & $\begin{array}{c}\text { 0.T. } \\
\text { (hh:mm:ss.cc) }\end{array}$ & Lat $\left(^{\circ}\right)$ & Lon $\left({ }^{\circ}\right)$ & $\begin{array}{c}\text { Depth } \\
(\mathrm{km})\end{array}$ & $\mathbf{M}_{\mathbf{d}}$ & $\mathbf{M}_{\mathrm{L}}$ & No & Gap $\left(^{\circ}\right)$ & Rms (s) & $\begin{array}{l}\text { ErrH } \\
(\mathrm{km})\end{array}$ & $\begin{array}{l}\text { ErrZ } \\
(\mathrm{km})\end{array}$ \\
\hline 1 & $17 / 11 / 2002$ & 23:06:33.43 & 37.94 & 15.43 & 2.2 & 1.6 & & 12 & 139 & 0.24 & 0.5 & 0.3 \\
\hline 2 & $17 / 04 / 2013$ & 05:18:21.12 & 37.94 & 15.44 & 8.8 & 1.3 & 1.5 & 16 & 140 & 0.25 & 0.4 & 0.4 \\
\hline 3 & $05 / 01 / 2003$ & $15: 53: 27.15$ & 37.79 & 15.39 & 8.9 & 2.7 & & 35 & 118 & 0.50 & 0.2 & 0.3 \\
\hline 4 & $11 / 10 / 2012$ & 19:53:08.83 & 37.80 & 15.39 & 16.9 & & 2.1 & 46 & 109 & 0.41 & 0.2 & 0.3 \\
\hline 5 & $01 / 12 / 2002$ & $01: 05: 50.55$ & 37.97 & 16.11 & 11.7 & 2.4 & & 9 & 212 & 0.26 & 0.8 & 0.9 \\
\hline 6 & 05/11/2012 & $15: 46: 48.87$ & 37.96 & 16.10 & 38.0 & & 1.9 & 10 & 205 & 0.23 & 0.7 & 0.6 \\
\hline 7 & $28 / 10 / 2002$ & $00: 11: 29.74$ & 37.53 & 14.85 & 3.0 & 1.6 & & 12 & 264 & 0.31 & 1.5 & 0.6 \\
\hline 8 & $18 / 07 / 2012$ & $00: 27: 27.75$ & 37.54 & 14.85 & 8.2 & & 2.7 & 55 & 84 & 0.39 & 0.2 & 0.2 \\
\hline 9 & $17 / 11 / 2002$ & 04:56:05.03 & 37.02 & 14.71 & 5.6 & 2.0 & & 16 & 282 & 0.26 & 0.5 & 0.5 \\
\hline 10 & $26 / 06 / 2012$ & $21: 26: 59.94$ & 37.01 & 14.70 & 3.2 & & 1.9 & 16 & 135 & 0.28 & 0.3 & 0.3 \\
\hline
\end{tabular}

Table 1. Comparison between couples of events having near locations (all earthquakes were located with data recorded from NEMO-SN1) and occurring in the two periods of NEMO-SN1 deployments (2002-2003 and 2012-2013) to test the performance of land seismic network. The ID numbers refer to the events shown in Figure 2. An improvement of locations due to the increase of the number of land seismic stations is visible only for earthquakes occurring on land.

\subsection{Magnitude homogenization}

Magnitude is an indicator of earthquake size that reflects the specific instrument used, as well as the features of the events. In the 2002-2003 period, duration magnitude $\left(\mathrm{M}_{\mathrm{d}}\right)$ was routinely used for magnitude estimation, while the local magnitude $\left(\mathrm{M}_{\mathrm{L}}\right)$ has been computed using signals of broad-band seismometers since 2005. In order to ensure homogeneity in our catalogue in terms of magnitude and to analyse the spatial distribution of magnitude of events during the two periods, we considered the amplitude data together with duration data for 266 earthquakes, as reported in the seismic catalogues. We derived a regression equation that was used to convert all magnitudes in our catalogue from $M_{d}$ to $M_{L}$. Figure 3a shows a fairly linear trend of $M_{d}$ versus $M_{L}$ in the magnitude range between 1.0 and 3.4; the value of correlation coefficient $(\mathrm{R})$ is also indicated. We used this regression equation to compute the local magnitude for our seismicity catalogue. The distribution of $\mathrm{M}_{\mathrm{L}}$ computed for the 1130 events is shown in Figure $3 b$. The $M_{L}$ values for the whole data set range between 0.9 and 4.5 (27 events have a recomputed $M_{L} \geqslant 3.5$ ) with a peak around the value of 2.0 (Figure $3 b$ ). 

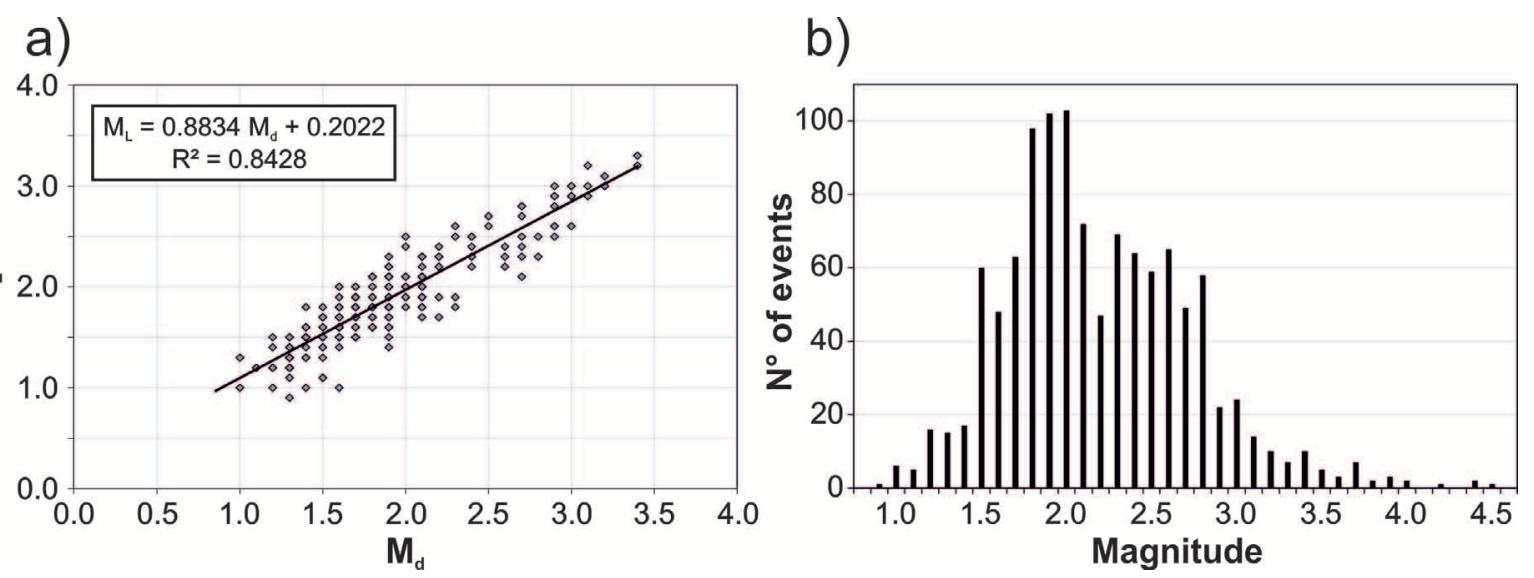

Figure 3. a) Regression equation of local magnitude versus duration magnitude for 266 earthquakes simultaneously recorded by both RSN and ERN. This regression was necessary to standardise the seismic catalogue and correlate the size of events to the tectonic structures. The solid line is the best fit to the data; the value of the correlation coefficient (R) is also indicated. b) Histogram of the local magnitude distribution of the 1130 events. The values range from 0.9 to 4.5 . with a peak at 2.0 .

\subsection{D locations and statistical analysis}

Since our aim is to demonstrate the improvement in offshore earthquake location, we concentrated on the seismicity occurring in the Ionian Sea and in the coastal area of eastern Sicily and southern Calabria, extracting from our integrated catalogue 358 crustal and sub-crustal events out of the 1130 relocated earthquakes. We compared locations performed with and without the use of travel times from NEMO-SN1. Figure 4 shows maps and E-W and NS sections related to the locations with (Figure 4a) and without (Figure 4b) data from NEMO-SN1. The seismicity is prevalently clustered near the coasts of eastern Sicily and south Calabria, while, in the offshore, earthquakes occurred at or near the main tectonic structures of the Malta escarpment, Ionian and Alfeo-Etna Faults (Figure 4a-b).

The use of the combined network of land stations and NEMO-SN1 has improved the earthquake locations in terms of azimuthal GAP as well as horizontal and vertical errors, and partially on root mean square (rms). The presence of a single seafloor station allowed us to significantly decrease the Mean (M) and Standard Deviation (SD) values computed on GAP, horizontal (ErrH) and vertical (ErrZ) errors, while a rough decrease of Standard Deviation (SD) is also observed on rms values (Figure 5). Average GAP for the 358 events decreases from $\mathrm{M}=199^{\circ}(\mathrm{SD}=66)$ of locations without NEMO-SN1 to $\mathrm{M}=180^{\circ}$ ( $\mathrm{SD}=63$ ) of locations with NEMO-SN1 (Figure 5a). Most events have consistent decreases of GAP up to $143^{\circ}$, as for the earthquake on August, 8, $2012\left(\mathrm{M}_{\mathrm{L}}=1.6\right)$. Average rms for all events span from $\mathrm{M}=0.27 \mathrm{~s}(\mathrm{SD}=0.10)$ of locations without NEMO-SN1 to $0.30 \mathrm{~s}(\mathrm{M})$ of locations with NEMO-SN1 (SD=0.09) (Figure $5 b$ ). The horizontal (ErrH) and vertical (ErrZ) errors of locations without NEMO-SN1 are characterized by $\mathrm{M}=1.36 \mathrm{~km}(\mathrm{SD}=7.43)$ and $\mathrm{M}=2.82 \mathrm{~km}(\mathrm{SD}=9.93)$, respectively. The horizontal and vertical errors of the location with NEMO SN1 are significantly lower: namely, ErrH is characterized by $\mathrm{M}=0.7(\mathrm{SD}=1.64)$ whereas ErrZ is characterized by $\mathrm{M}=1.24$ ( $\mathrm{SD}=5.53$ ) (Figures $5 \mathrm{c}, \mathrm{d}$ ).

We quantified the differences between locations with and without NEMO-SN1 travel times in terms of differences in latitude, longitude, and depth. Figures 6a-c-e show histograms indicating the differences in the ranges $-20 / 20 \mathrm{~km}$. As these differences are mainly concentrated in the $-5 /+5 \mathrm{~km}$ interval, we focused on these intervals, representing them in the maps of Figure $6 \mathrm{~b}-\mathrm{d}-\mathrm{f}$. We note that the locations with and without NEMO-SN1 are very similar in terms of areal distribution (Figures 6a-b and c-d), as latitude and longitude differences are below $4 \mathrm{~km}$ for about $95 \%$ and 94\% of events, respectively. Higher values are more evident in the peripheral areas where the coverage of the seafloor station appears to be less influential. On the other hand, the locations performed with and without NEMO-SN1 show greater differences in terms of hypocentre depths (Figures 6e-f), where over $95 \%$ of the events are characterized by roughly doubled depth differences (up to $10 \mathrm{~km}$ ). These differences are visible in the whole study area. 
Tiziana Sgroi et al.
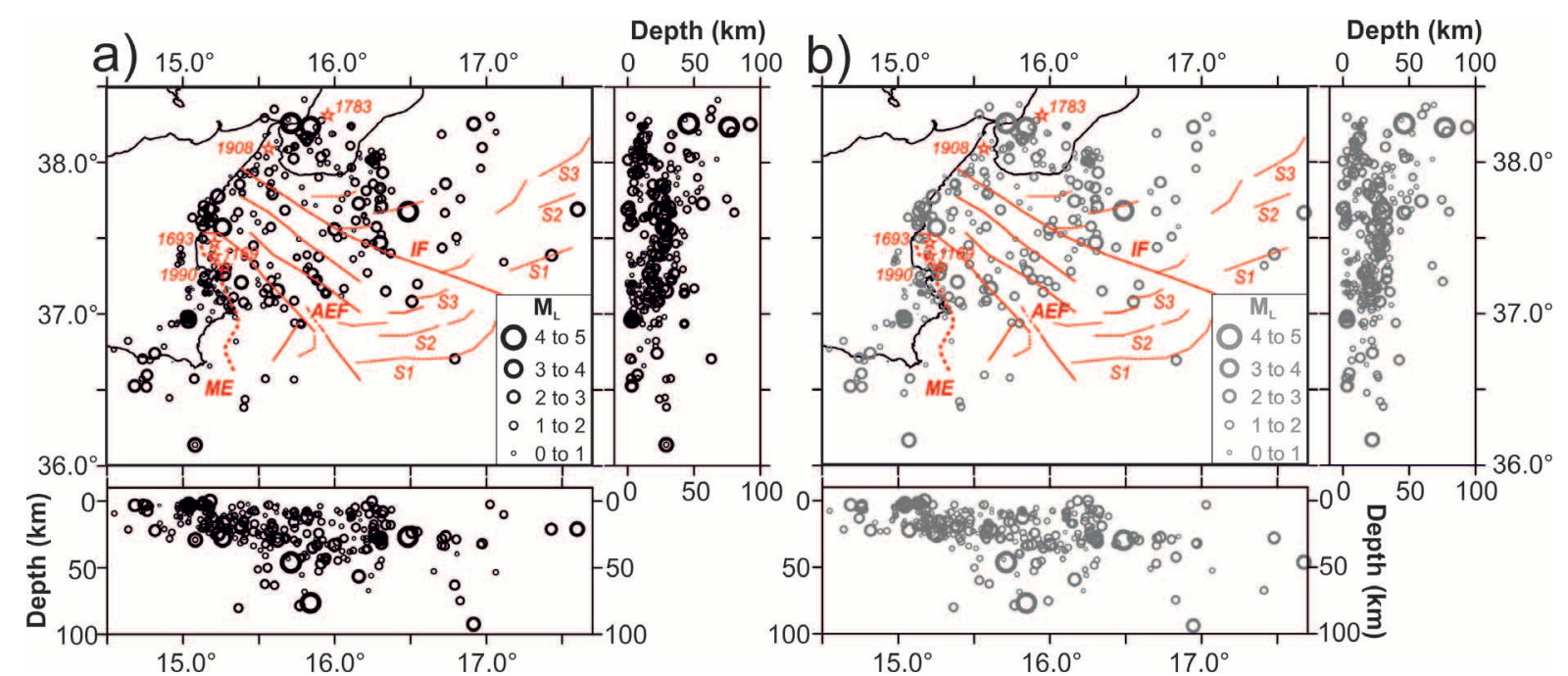

Figure 4. Comparison of 358 1D locations computed a) with NEMO-SN1 travel times (black circles) and b) without NEMOSN1 travel times (grey circles). Dimension of circles are proportional to the local magnitude recomputed above (see legend inside the maps). It is worth noting that the highest magnitude earthquakes of our catalogue occurred near the area where the five highest magnitude earthquakes were recorded in the past [1169, Mw 6.6; 1693, Mw 7.3; 1783 Mw 7.1; 1908, Mw 7.2; 1990, Mw 5.6; Boschi et al., 1997], indicated with red stars and years. In general, during the two deployment periods of NEMO-SN1, the offshore seismicity occurred prevalently along the main tectonic structures identified in the Ionian Sea (red sketched: Malta escarpment - ME, Alfeo-Etna Fault - AEF and Ionian Fault - IF, splay faults - S1, S2, S3).

a)

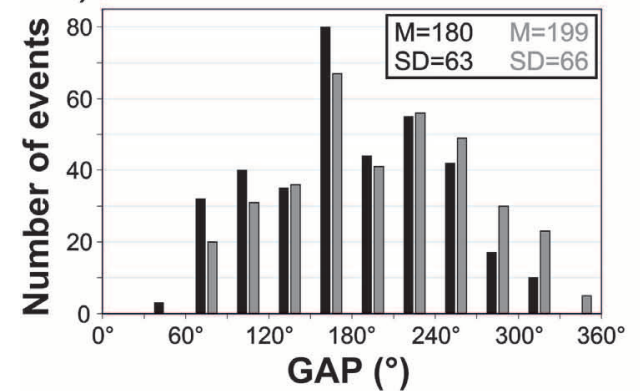

C)

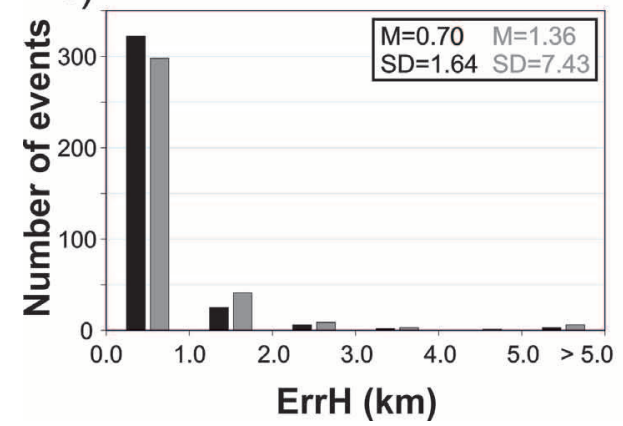

b)

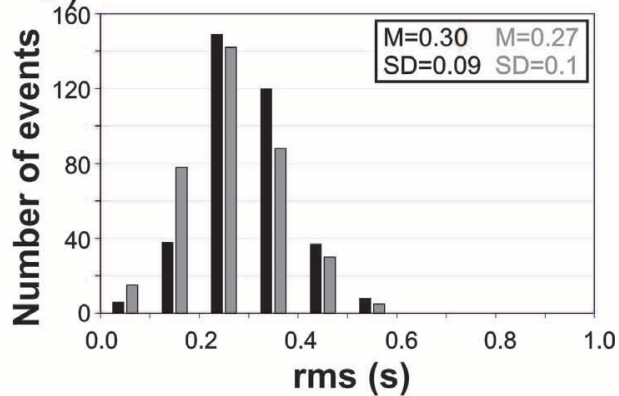

d)

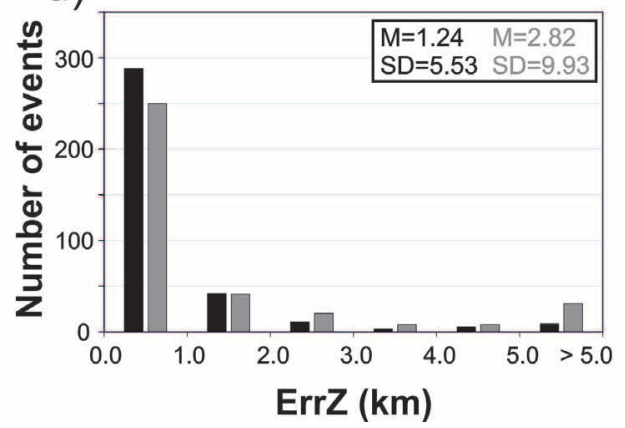

Figure 5. Quality statistics and comparison between a) GAP, b) rms, and c) horizontal (ErrH) and d) vertical (ErrZ) errors from locations with NEMO-SN1 data (black histograms) and without NEMO-SN1 data (grey histograms). Mean (M) and Standard Deviation (SD) computed for these parameters and compared for locations with (black) and without (grey) NEMO-SN1 data are reported inside the rectangular areas. The presence of a single seafloor station contributes to improving the location of events occurring offshore, through the decrease of the azimuthal gap and the associated location errors. 

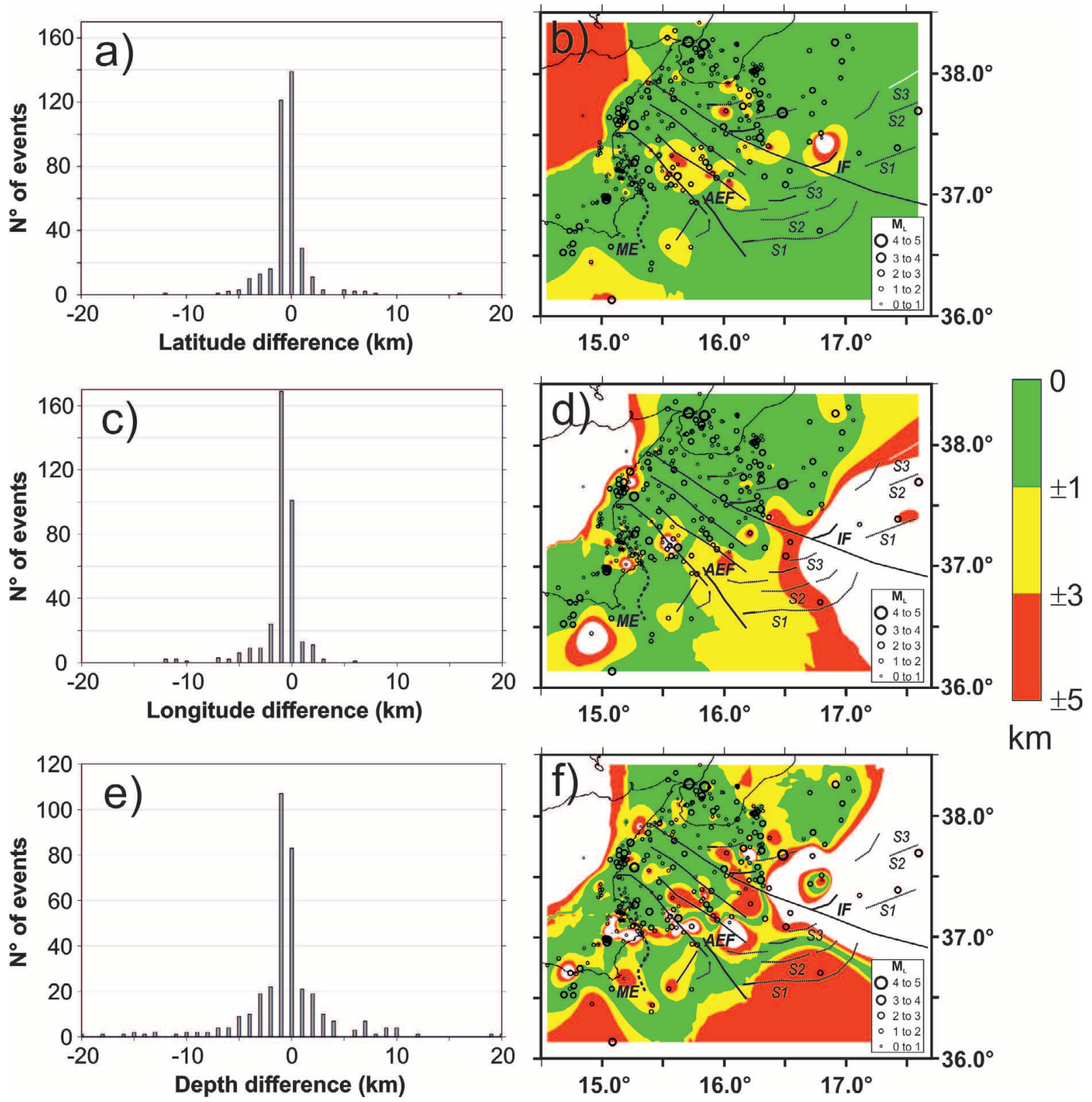

Figure 6. Differences in terms of latitude a), b), longitude c), d) and depth e), f) between locations performed with and without NEMO-SN1. Histograms show that the main differences in latitude a) and longitude c) are within $\pm 5 \mathrm{~km}$, while the differences in depth e) are roughly doubled. The distribution of these differences within the values of $\pm 5 \mathrm{~km}$ is indicated in the three maps (b), latitude; d), longitude; f), depth). Latitude and longitude have similar values in the central part of the study area, showing higher values in the peripheral areas, while differences in hypocentre depth are more consistent in the whole study area. Dots indicate the locations performed with data of NEMO-SN1 and their dimensions are proportional to the recomputed $\mathrm{M}_{\mathrm{L}}$. The main tectonic structures (Malta escarpment - ME, Alfeo-Etna Fault - AEF and Ionian Fault - IF, splay faults - S1, S2, S3) are sketched in black.

\subsection{Location residuals}

To detail the crustal and lithospheric structure of eastern Sicily and the Ionian Sea and focus on the importance of the seafloor observatory in defining the crustal structures in the offshore, we analysed the travel-time residuals (Figure 7) computed from the locations performed with land stations and the seafloor observatory data. The criteria 


\section{Tiziana Sgroi et al.}

used for the data selection are designed to be less than $100 \mathrm{~km}$ in depth and with an epicentre distance less than 400 $\mathrm{km}$; within this window the whole dataset was obtained, considering a total of $4732 \mathrm{P}$-wave arrivals.

$\mathrm{P}$-wave residuals indicate the complex velocity pattern of a region, as strong lateral velocity non-homogeneities and the passage from low to high velocity zones are required to explain the observed pattern of residuals. The travel-time residuals reflect the difference between actual and estimated model velocities along ray paths to stations and can compensate for heterogeneous velocity structures near individual stations. In this study, P-residuals computed on all stations enable focusing on the structural pattern in the Ionian and Tyrrhenian basins, around the coasts of Sicily and Calabria and in the inner areas of the two regions. Figure 7 shows the distribution of P-wave travel-time residuals for six depth intervals. The transition from high velocity (negative residuals) to low velocity (positive residuals) together with the relocations of earthquakes, reflect clearly the main seismogenic structures that can be defined in the morpho-structural domains within the Calabrian accretionary prism in the Ionian Sea [Polonia et al., 2011]. Low velocities associated with Mt. Etna volcanism, showing continuity also in the offshore, are represented well by the positive residuals shown in Figure 7. The most impressive result concerns the transition from high to low velocities in the Ionian basin that corresponds to the position of the pre-Messinian wedge of the inner deformation front [Polonia et al., 2011; 2013].
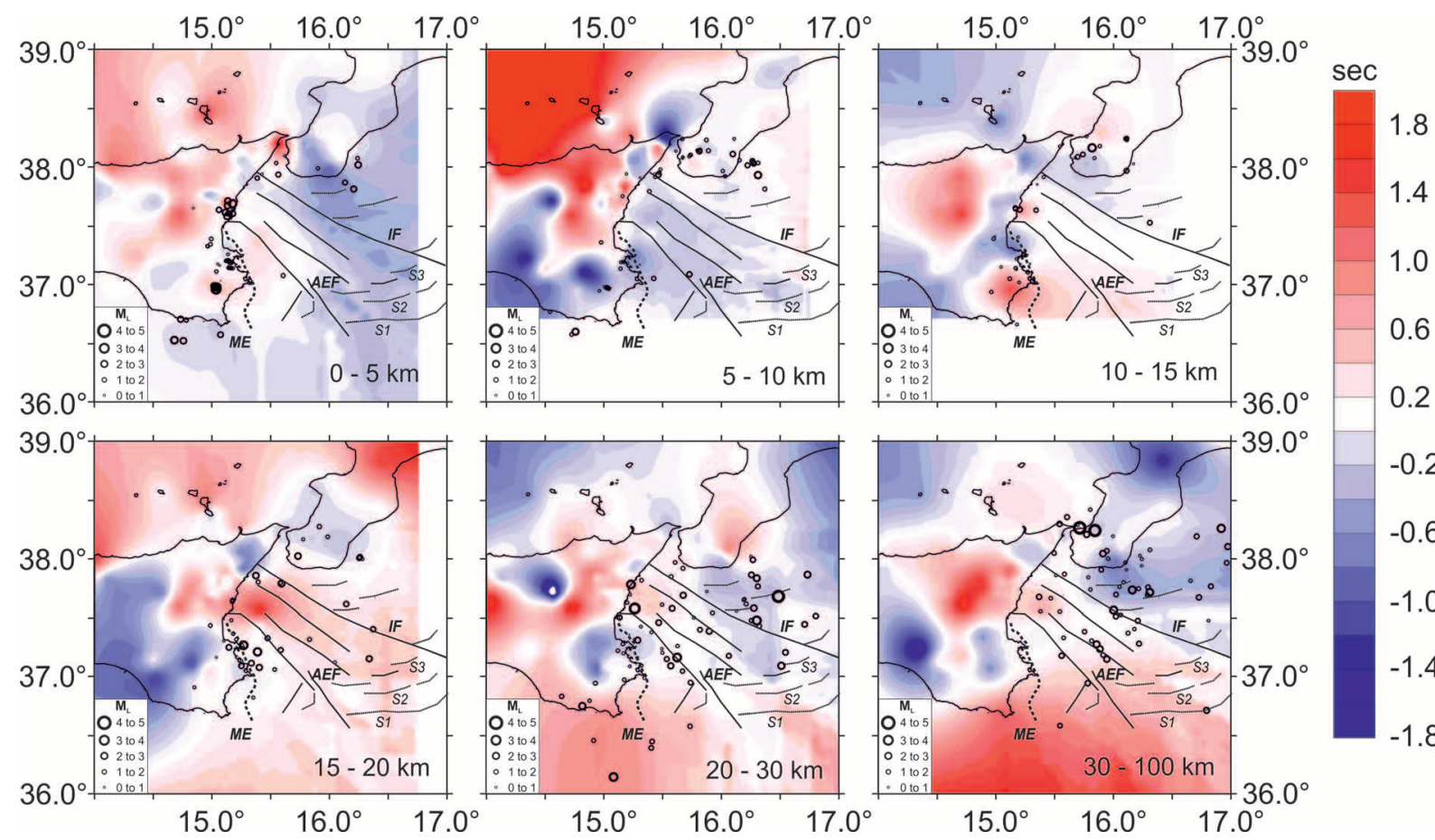

Figure 7. P-wave travel time residuals computed from the locations performed with land stations and the seafloor observatory data. The blue areas indicate fast residuals (high velocities); the red ones slow residuals (low velocities). Six layers are considered and earthquakes occurring in each layer are shown with circles proportional to the recomputed magnitude. The pattern of residuals is indicative of the crustal tectonic and volcanic structures in the onshore and offshore areas of Sicily and Calabria. The main tectonic structures (Malta escarpment - ME, Alfeo-Etna Fault - AEF and Ionian Fault - IF, splay faults - S1, S2, S3) are sketched in black.

\subsection{D locations}

To test the quality of locations performed with and without NEMO-SN1 data, the dataset of 358 events was relocated using a new 3D velocity model computed for the Western Ionian Sea [Sgroi et al., 2021] and the tomoDDPS algorithm [Zhang et al., 2009]. 
The 3D velocity model derived from a detailed 3D image of the Calabrian-Ionian subduction system [Sgroi et al., 2021] and was obtained by seismic tomography. In these images, the Moho depth can be observed at about $20 \mathrm{~km}$ in the Ionian basin, while near the coast the Moho deepens up about $30 \mathrm{~km}$. This model, the result of the first inversion performed with marine data, investigated the offshore tectonic structures with unprecedented detail with respect to previous tomographic studies. Moreover, the study area is well resolved in the higher part of the model (up to $40 \mathrm{~km}$ depth) and in the western-central part of the Ionian Sea, due to the single seafloor station that assures the good event-station geometry in spite of the lack of coverage by seismic stations.

We used the tomoDDPS algorithm [Zhang et al., 2009] to perform 3D locations since it has the advantage of using a combination of both absolute and differential arrival time readings, so that for earthquakes with foci lying close to each other, travel times errors due to incorrect velocity models in the volume outside the cluster will effectively be cancelled. Furthermore, the algorithm produced a better clustering of earthquakes, allowing the relocation of 352 earthquakes out of 358 of $1 \mathrm{D}$ locations. Earthquake relocations (map and on E-W and N-S sections) using the 3D velocity model are shown in Figure 8. The seismicity in the Ionian Sea is rather diffuse, with the majority of earthquakes to be located are close to the Malta escarpment (ME), in the outer regions of the IF and AEF systems and in the Hyblean and Messina Strait areas. The main cluster of earthquakes is related to seismicity occurring in the onshore area of the Hyblean plateau; other minor clusters are visible near the coastal area of Mt. Etna, and onshore and offshore southern and south-eastern Calabria. The map of distribution of earthquakes reflects the $1 \mathrm{D}$ locations, while major differences are evident in the $\mathrm{E}-\mathrm{W}$ and N-S sections. The $\mathrm{E}-\mathrm{W}$ and N-S sections show the distribution of earthquakes up to $100 \mathrm{~km}$ depth. The shallowest events (down to $20 \mathrm{~km}$ ) are concentrated on land and in the coastal area; deeper events (down to $60 \mathrm{~km}$ ) prevail in the Ionian basin.

The two E-W and N-S sections (Figure 8) contribute to highlighting the depth distribution of seismicity in relation to the main fault systems and structures. As a matter of fact, the main differences in the distribution of earthquakes based on the 3D velocity model (Figure 8) with respect to 1D locations (Figure 4) are related to the sharp transition between the southwestern region, where earthquakes enucleate at about $20-\mathrm{km}$ depth, and the region toward NE where earthquakes reach over 50-60 km of depth.

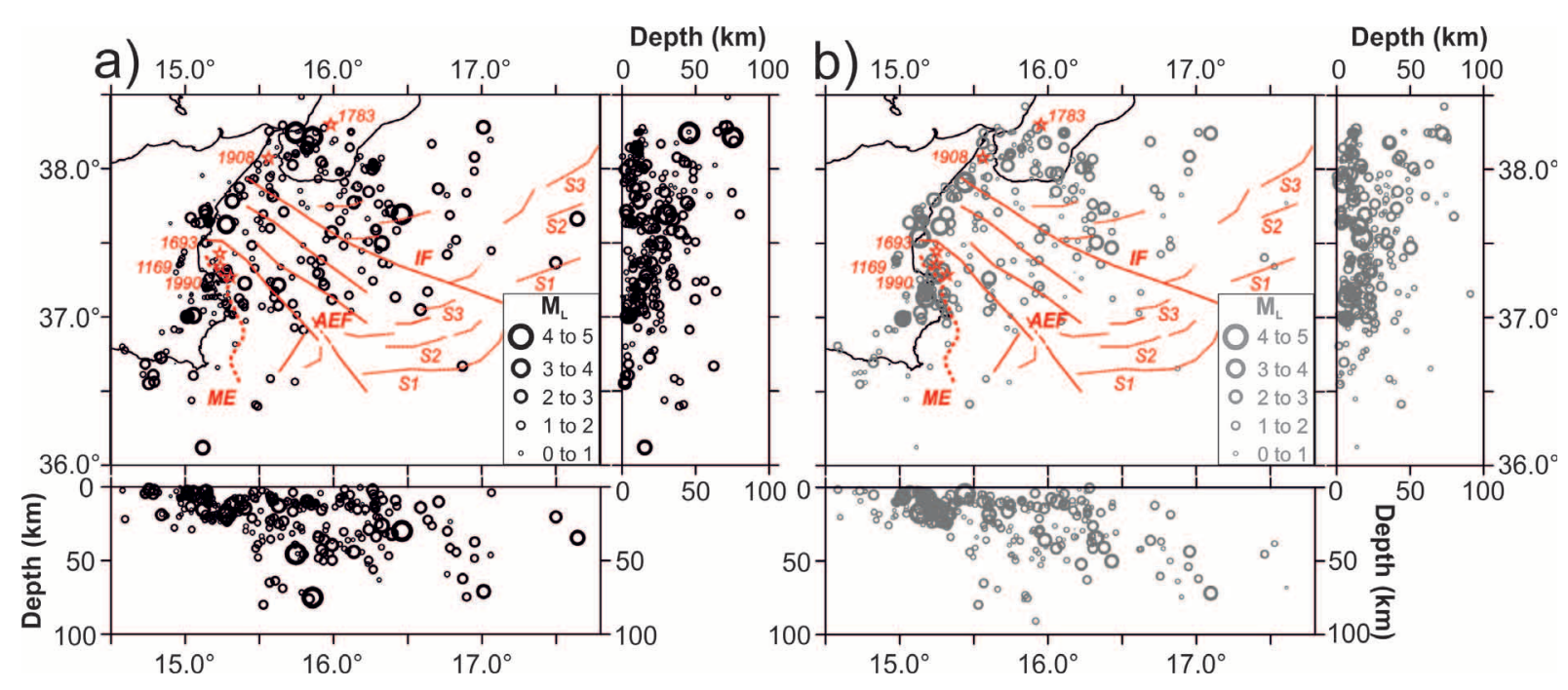

Figure 8. Comparison of 352 3D locations computed a) with NEMO-SN1 (black circles) and b) without NEMO-SN1 (grey circles). Dimension of circles are proportional to the recomputed local magnitude (see legend inside the maps). Differences between 1D and 3D locations are perceptible in terms of hypocentre depths. As in the 1D locations computed with NEMO-SN1 travel times, the highest magnitude earthquakes occurred near the area where the five highest magnitude earthquakes were recorded in the past, indicated with red stars and years [1169, Mw 6.6; 1693, Mw 7.3; 1783 Mw 7.1; 1908, Mw 7.2; 1990, Mw 5.6; Boschi et al., 1997] and along the main tectonic structures, including Malta escarpment (ME), Alfeo-Etna Fault (AEF) and Ionian Fault [IF; Polonia et al., 2016], and splay faults (S1, S2, S3) (red sketched). 


\section{Tiziana Sgroi et al.}

\subsection{Focal mechanisms}

To infer the kinematics of earthquakes occurring in the Ionian basin and thoroughly evaluate the effect using NEMO-SN1, we computed 73 new focal mechanisms $\left(1.6 \leqslant \mathrm{M}_{\mathrm{L}} \leqslant 4.5\right)$, taking into account the polarity detected from the NEMO-SN1 seafloor station during the handpicking procedure. We applied the FPFIT standard procedure [Reasenberg and Oppenheimer, 1985], considering the polarities of events occurring in the Ionian Sea area in the two time periods. The FPFIT conventional procedure is based on P wave polarity data and on their spatial distribution over the focal sphere. Of 73 focal mechanisms, 71 earthquakes have a minimum number of eight clear polarities and the other two events, having seven polarities, have been included in our dataset due to their clear mechanism. The polarities are homogenously distributed over the focal sphere (approximately $75 \%$ of events have a number of polarities $\geq 10$ ) and with discrepant polarities $\leq 2$ (about $71 \%$ of earthquakes do not have discrepant polarities). We defined the quality factor (Q) of focal solutions, depending on the degree of polarity misfit and on the range of uncertainties in the strike, dip, and rake values. $Q$ ranges from 0 (low quality) to 2 (best quality). In our dataset, 37 mechanisms have $Q=2,34$ have $Q=1$, and only 2 solutions have $Q=0$. The 73 focal mechanisms computed in this work are shown in Figure 9 and listed in Table 2.

\begin{tabular}{|c|c|c|c|c|c|c|c|c|c|c|c|c|c|c|c|c|c|}
\hline \multirow{2}{*}{$\mathbf{N}$} & \multirow{2}{*}{$\begin{array}{c}\text { DATE } \\
(\mathrm{dd} / \mathrm{mm} / \mathrm{yyyy})\end{array}$} & \multirow{2}{*}{$\begin{array}{c}\text { O.T. } \\
\text { (hh:mm:ss) }\end{array}$} & \multirow{2}{*}{$\begin{array}{l}\text { LAT } \\
\left({ }^{\circ} \mathrm{N}\right)\end{array}$} & \multirow{2}{*}{$\begin{array}{l}\text { LON } \\
\left({ }^{\circ} \mathrm{E}\right)\end{array}$} & \multirow{2}{*}{$\begin{array}{c}\text { DEPTH } \\
(\mathrm{km})\end{array}$} & \multirow{2}{*}{ ML } & \multirow{2}{*}{$\begin{array}{c}\mathbf{N} \\
\text { polar }\end{array}$} & \multirow{2}{*}{$\begin{array}{c}\mathbf{N} \\
\text { disc }\end{array}$} & \multicolumn{3}{|c|}{ PLANE 1} & \multicolumn{2}{|c|}{ P-AXIS } & \multicolumn{2}{|c|}{ T-AXIS } & \multirow{2}{*}{$\mathbf{Q}$} & \multirow{2}{*}{ Cat } \\
\hline & & & & & & & & & STRK $\left({ }^{\circ}\right)$ & DIP $\left({ }^{\circ}\right)$ & RAKE $\left({ }^{\circ}\right)$ & AZM & PLNG & AZM & PLNG & & \\
\hline 1 & 28/11/2002 & 00:00:28 & 37.217 & 15.628 & 12.67 & 3.4 & 13 & 0 & 160 & 55 & -70 & 121 & 72 & 236 & 8 & 1 & $\mathrm{NF}$ \\
\hline 2 & $02 / 12 / 2002$ & $12: 28: 13$ & 37.715 & 15.139 & 2.91 & 3.3 & 8 & 0 & 130 & 20 & -100 & 237 & 65 & 48 & 25 & 1 & $\mathrm{NF}$ \\
\hline 3 & $12 / 02 / 2003$ & $08: 57: 17$ & 37.874 & 15.365 & 8.79 & 2.8 & 13 & 1 & 80 & 85 & 10 & 214 & 3 & 305 & 11 & 1 & SS \\
\hline 4 & $15 / 06 / 2012$ & $06: 27: 25$ & 37.498 & 16.325 & 26.19 & 3.5 & 16 & 1 & 155 & 65 & -50 & 113 & 52 & 217 & 11 & 2 & NS \\
\hline 5 & $16 / 06 / 2012$ & $06: 21: 53$ & 37.320 & 15.280 & 23.11 & 2.7 & 15 & 0 & 120 & 65 & -80 & 50 & 68 & 203 & 19 & 2 & $\mathrm{NF}$ \\
\hline 6 & $25 / 06 / 2012$ & $10: 52: 49$ & 37.005 & 15.013 & 2.81 & 3.0 & 8 & 0 & 280 & 80 & 180 & 145 & 7 & 235 & 7 & 2 & SS \\
\hline 7 & $27 / 06 / 2012$ & 01:07:37 & 36.998 & 15.021 & 4.68 & 2.2 & 10 & 0 & 15 & 90 & 10 & 150 & 7 & 240 & 7 & 1 & SS \\
\hline 8 & $27 / 06 / 2012$ & 01:14:19 & 37.011 & 15.055 & 4.73 & 3.7 & 26 & 0 & 185 & 85 & 20 & 317 & 10 & 51 & 18 & 1 & SS \\
\hline 9 & $27 / 06 / 2012$ & $01: 20: 58$ & 37.003 & 15.018 & 3.33 & 3.0 & 9 & 0 & 95 & 80 & -170 & 319 & 14 & 49 & 0 & 1 & SS \\
\hline 10 & $27 / 06 / 2012$ & 02:48:00 & 37.003 & 15.014 & 3.47 & 3.3 & 19 & 2 & 90 & 75 & 170 & 316 & 4 & 47 & 18 & 1 & SS \\
\hline 11 & $17 / 07 / 2012$ & $11: 22: 39$ & 38.007 & 16.282 & 14.65 & 2.5 & 11 & 0 & 85 & 30 & -40 & 89 & 57 & 319 & 23 & 1 & NS \\
\hline 12 & $28 / 07 / 2012$ & $02: 51: 23$ & 37.076 & 15.628 & 24.77 & 2.7 & 11 & 0 & 145 & 50 & -50 & 122 & 60 & 28 & 2 & 2 & NS \\
\hline 13 & $17 / 08 / 2012$ & 09:29:02 & 37.091 & 15.391 & 12.21 & 2.7 & 11 & 1 & 275 & 80 & -160 & 140 & 21 & 47 & 7 & 0 & SS \\
\hline 14 & $18 / 08 / 2012$ & $11: 27: 34$ & 37.520 & 16.826 & 44.25 & 2.5 & 11 & 0 & 30 & 70 & 0 & 347 & 14 & 253 & 14 & 1 & SS \\
\hline 15 & $18 / 08 / 2012$ & $22: 23: 02$ & 37.322 & 15.209 & 18.91 & 1.9 & 9 & 0 & 65 & 55 & 0 & 26 & 24 & 284 & 24 & 0 & SS \\
\hline 16 & $25 / 08 / 2012$ & $21: 33: 31$ & 37.942 & 15.569 & 5.71 & 2.4 & 10 & 0 & 45 & 50 & 60 & 156 & 1 & 248 & 67 & 2 & TF \\
\hline 17 & $28 / 08 / 2012$ & $23: 12: 15$ & 38.244 & 15.746 & 45.50 & 4.5 & 30 & 0 & 25 & 60 & -180 & 246 & 21 & 344 & 21 & 2 & SS \\
\hline 18 & 13/09/2012 & $20: 47: 27$ & 37.099 & 15.266 & 13.23 & 2.0 & 8 & 0 & 60 & 35 & -80 & 113 & 78 & 323 & 10 & 2 & $\mathrm{NF}$ \\
\hline 19 & $17 / 09 / 2012$ & 02:53:41 & 37.932 & 15.896 & 48.24 & 2.3 & 20 & 0 & 350 & 35 & -50 & 355 & 63 & 232 & 16 & 2 & $\mathrm{NF}$ \\
\hline 20 & $22 / 09 / 2012$ & $17: 25: 09$ & 37.851 & 16.072 & 41.92 & 1.9 & 10 & 0 & 5 & 85 & -30 & 317 & 24 & 55 & 17 & 1 & SS \\
\hline 21 & $27 / 09 / 2012$ & $06: 44: 26$ & 37.294 & 15.899 & 34.00 & 2.9 & 20 & 0 & 115 & 50 & -150 & 322 & 46 & 64 & 11 & 1 & NS \\
\hline 22 & $30 / 09 / 2012$ & $06: 31: 31$ & 37.497 & 15.164 & 18.57 & 1.8 & 10 & 0 & 40 & 25 & -90 & 130 & 70 & 310 & 20 & 2 & $\mathrm{NF}$ \\
\hline 23 & $11 / 10 / 2012$ & 19:53:08 & 37.818 & 15.398 & 10.49 & 2.3 & 24 & 1 & 70 & 45 & 80 & 347 & 0 & 254 & 83 & 2 & TF \\
\hline 24 & $12 / 10 / 2012$ & $13: 12: 28$ & 37.687 & 16.784 & 41.40 & 2.5 & 13 & 0 & 25 & 45 & -50 & 11 & 62 & 268 & 7 & 1 & $\mathrm{NF}$ \\
\hline 25 & $18 / 10 / 2012$ & 06:18:48 & 37.281 & 15.177 & 20.29 & 2.0 & 8 & 0 & 200 & 30 & -90 & 290 & 75 & 110 & 15 & 2 & $\mathrm{NF}$ \\
\hline 26 & 19/10/2012 & $18: 37: 18$ & 37.126 & 15.363 & 13.26 & 2.6 & 11 & 0 & 170 & 55 & -30 & 138 & 44 & 42 & 7 & 2 & NS \\
\hline 27 & $26 / 10 / 2012$ & $13: 21: 30$ & 36.999 & 15.013 & 5.31 & 2.8 & 8 & 0 & 90 & 80 & -170 & 314 & 14 & 44 & 0 & 1 & SS \\
\hline 28 & $01 / 11 / 2012$ & 19:03:47 & 38.013 & 16.228 & 52.26 & 1.8 & 13 & 0 & 135 & 65 & -180 & 357 & 17 & 93 & 17 & 1 & SS \\
\hline 29 & 09/11/2012 & $13: 52: 36$ & 37.937 & 15.655 & 27.31 & 2.1 & 13 & 0 & 55 & 90 & -140 & 288 & 27 & 182 & 27 & 2 & SS \\
\hline 30 & $13 / 11 / 2012$ & 07:06:33 & 38.214 & 15.857 & 75.10 & 4.4 & 22 & 1 & 110 & 55 & -150 & 322 & 44 & 58 & 7 & 2 & NS \\
\hline 31 & $18 / 11 / 2012$ & $02: 37: 29$ & 37.485 & 15.796 & 15.23 & 1.8 & 11 & 0 & 200 & 80 & -50 & 147 & 41 & 260 & 24 & 1 & NS \\
\hline 32 & $18 / 11 / 2012$ & 05:06:09 & 37.049 & 15.577 & 9.05 & 2.0 & 11 & 1 & 135 & 55 & -30 & 103 & 44 & 7 & 7 & 1 & NS \\
\hline 33 & $24 / 11 / 2012$ & $23: 38: 57$ & 37.588 & 16.285 & 33.56 & 2.8 & 28 & 0 & 115 & 60 & -140 & 330 & 48 & 238 & 2 & 2 & NS \\
\hline 34 & $25 / 11 / 2012$ & 12:11:30 & 37.918 & 15.444 & 4.03 & 1.9 & 20 & 1 & 60 & 55 & 70 & 164 & 8 & 279 & 72 & 1 & TF \\
\hline 35 & $04 / 12 / 2012$ & $15: 39: 22$ & 37.668 & 15.147 & 4.72 & 2.0 & 7 & 0 & 150 & 25 & -90 & 240 & 70 & 60 & 20 & 1 & $\mathrm{NF}$ \\
\hline 36 & $07 / 12 / 2012$ & $10: 23: 23$ & 37.933 & 15.477 & 8.62 & 1.9 & 9 & 1 & 355 & 70 & 20 & 307 & 1 & 216 & 28 & 2 & SS \\
\hline 37 & $10 / 12 / 2012$ & $23: 39: 17$ & 37.072 & 15.518 & 2.32 & 2.1 & 9 & 0 & 165 & 60 & -30 & 130 & 41 & 37 & 3 & 1 & NS \\
\hline 38 & $24 / 12 / 2012$ & $16: 29: 47$ & 38.082 & 15.690 & 9.87 & 2.3 & 13 & 0 & 0 & 30 & -110 & 137 & 71 & 285 & 16 & 1 & $\mathrm{NF}$ \\
\hline 39 & $27 / 12 / 2012$ & $22: 21: 54$ & 37.146 & 16.104 & 13.08 & 2.4 & 16 & 1 & 125 & 50 & -40 & 100 & 53 & 2 & 6 & 1 & NS \\
\hline 40 & $28 / 12 / 2012$ & 08:55:38 & 37.384 & 15.918 & 15.78 & 2.7 & 26 & 1 & 175 & 65 & -40 & 135 & 45 & 232 & 6 & 2 & NS \\
\hline 41 & $29 / 12 / 2012$ & $04: 29: 26$ & 37.262 & 15.159 & 20.22 & 2.6 & 11 & 0 & 140 & 15 & -30 & 155 & 51 & 1 & 36 & 2 & $\mathrm{HV}$ \\
\hline 42 & $30 / 12 / 2012$ & 19:32:01 & 37.483 & 15.449 & 21.10 & 2.6 & 26 & 0 & 85 & 85 & -160 & 311 & 18 & 217 & 10 & 2 & SS \\
\hline 43 & 07/01/2013 & $14: 34: 07$ & 37.710 & 15.663 & 23.17 & 2.7 & 29 & 0 & 150 & 50 & -60 & 127 & 67 & 219 & 1 & 2 & $\mathrm{NF}$ \\
\hline 44 & 09/01/2013 & 10:02:09 & 37.523 & 15.951 & 26.28 & 2.1 & 13 & 0 & 170 & 80 & -20 & 125 & 21 & 218 & 7 & 1 & SS \\
\hline 45 & $17 / 01 / 2013$ & 01:08:42 & 37.816 & 15.362 & 17.68 & 2.0 & 8 & 1 & 290 & 90 & 170 & 335 & 7 & 245 & 7 & 1 & SS \\
\hline 46 & 19/01/2013 & $02: 43: 44$ & 37.600 & 15.572 & 22.80 & 2.6 & 22 & 2 & 195 & 85 & -30 & 147 & 24 & 245 & 17 & 2 & SS \\
\hline 47 & $01 / 02 / 2013$ & $20: 36: 20$ & 37.791 & 16.168 & 31.71 & 2.1 & 10 & 0 & 50 & 55 & -60 & 17 & 65 & 119 & 6 & 1 & $\mathrm{NF}$ \\
\hline 48 & $02 / 02 / 2013$ & $16: 23: 27$ & 37.330 & 15.468 & 7.25 & 2.4 & 14 & 0 & 165 & 70 & -40 & 122 & 42 & 222 & 11 & 1 & NS \\
\hline
\end{tabular}


NEMO-SN1 improves earthquake locations

\begin{tabular}{|c|c|c|c|c|c|c|c|c|c|c|c|c|c|c|c|c|c|}
\hline 49 & $07 / 02 / 2013$ & $19: 42: 41$ & 37.931 & 15.420 & 7.57 & 1.8 & 9 & 1 & 345 & 45 & -160 & 191 & 42 & 300 & 19 & 2 & NS \\
\hline 50 & $28 / 02 / 2013$ & $10: 51: 11$ & 38.137 & 15.823 & 9.20 & 2.5 & 7 & 0 & 115 & 60 & -60 & 74 & 62 & 184 & 10 & 2 & NF \\
\hline 51 & $28 / 02 / 2013$ & $20: 14: 37$ & 37.572 & 15.988 & 39.37 & 3.2 & 30 & 2 & 30 & 90 & 10 & 165 & 7 & 255 & 7 & 2 & SS \\
\hline 52 & 03/03/2013 & $23: 39: 12$ & 38.140 & 15.821 & 9.88 & 3.3 & 14 & 0 & 55 & 20 & -60 & 98 & 61 & 302 & 27 & 2 & $\mathrm{NF}$ \\
\hline 53 & $11 / 03 / 2013$ & 10:18:21 & 37.227 & 15.402 & 14.40 & 3.3 & 21 & 1 & 155 & 55 & -50 & 124 & 58 & 218 & 2 & 2 & NS \\
\hline 54 & $12 / 03 / 2013$ & $13: 49: 43$ & 37.762 & 16.303 & 25.34 & 2.4 & 13 & 0 & 185 & 5 & 80 & 104 & 40 & 286 & 50 & 2 & $\mathrm{HV}$ \\
\hline 55 & $21 / 03 / 2013$ & $22: 03: 05$ & 37.279 & 15.276 & 16.50 & 3.4 & 20 & 1 & 20 & 80 & 40 & 145 & 19 & 249 & 35 & 2 & TS \\
\hline 56 & $23 / 03 / 2013$ & $06: 22: 44$ & 37.126 & 15.295 & 22.34 & 1.6 & 8 & 0 & 75 & 75 & -150 & 299 & 32 & 203 & 9 & 1 & NS \\
\hline 57 & $24 / 03 / 2013$ & $15: 47: 22$ & 37.694 & 16.461 & 29.86 & 4.4 & 42 & 1 & 160 & 50 & -70 & 135 & 74 & 236 & 3 & 2 & $\mathrm{NF}$ \\
\hline 58 & $24 / 03 / 2013$ & $20: 37: 49$ & 37.715 & 16.391 & 31.90 & 3.1 & 20 & 0 & 5 & 15 & -90 & 95 & 60 & 275 & 30 & 1 & $\mathrm{NF}$ \\
\hline 59 & $25 / 03 / 2013$ & 20:11:06 & 37.763 & 16.371 & 46.79 & 2.3 & 8 & 0 & 115 & 60 & -140 & 330 & 48 & 238 & 2 & 1 & NS \\
\hline 60 & $28 / 03 / 2013$ & $16: 40: 14$ & 37.429 & 15.335 & 19.38 & 1.7 & 11 & 0 & 100 & 75 & -150 & 324 & 32 & 228 & 9 & 1 & NS \\
\hline 61 & $02 / 04 / 2013$ & 01:10:51 & 37.815 & 15.589 & 8.61 & 2.9 & 28 & 0 & 135 & 80 & 170 & 1 & 0 & 91 & 14 & 2 & SS \\
\hline 62 & $02 / 04 / 2013$ & $18: 38: 10$ & 37.850 & 15.575 & 24.46 & 2.1 & 9 & 0 & 290 & 90 & -170 & 155 & 7 & 65 & 7 & 1 & SS \\
\hline 63 & $04 / 04 / 2013$ & $05: 26: 29$ & 37.818 & 15.580 & 11.28 & 2.0 & 12 & 0 & 175 & 55 & -90 & 85 & 80 & 265 & 10 & 2 & NF \\
\hline 64 & $04 / 04 / 2013$ & $11: 12: 28$ & 37.084 & 15.279 & 21.51 & 2.5 & 12 & 0 & 10 & 75 & 30 & 138 & 9 & 234 & 32 & 2 & TS \\
\hline 65 & $06 / 04 / 2013$ & 02:47:57 & 37.769 & 15.787 & 29.98 & 1.9 & 14 & 0 & 180 & 60 & -50 & 143 & 55 & 243 & 7 & 2 & NS \\
\hline 66 & $07 / 04 / 2013$ & $02: 22: 45$ & 37.269 & 15.247 & 15.69 & 2.1 & 9 & 0 & 150 & 70 & -20 & 109 & 28 & 18 & 1 & 2 & SS \\
\hline 67 & 09/04/2013 & $07: 25: 10$ & 38.048 & 15.916 & 42.41 & 2.8 & 19 & 1 & 65 & 80 & -170 & 289 & 14 & 19 & 0 & 1 & SS \\
\hline 68 & 09/04/2013 & $12: 55: 24$ & 37.375 & 15.185 & 18.50 & 1.9 & 10 & 1 & 115 & 25 & -60 & 151 & 64 & 3 & 22 & 1 & NF \\
\hline 69 & $11 / 04 / 2013$ & 19:47:09 & 37.499 & 15.138 & 18.47 & 2.4 & 17 & 0 & 130 & 50 & -70 & 105 & 74 & 206 & 3 & 1 & NF \\
\hline 70 & $17 / 04 / 2013$ & 05:58:34 & 37.638 & 15.508 & 16.23 & 1.9 & 11 & 0 & 280 & 85 & -140 & 151 & 31 & 46 & 23 & 2 & NS \\
\hline 71 & $17 / 04 / 2013$ & $08: 15: 52$ & 37.656 & 15.486 & 24.54 & 2.0 & 9 & 0 & 120 & 85 & 100 & 201 & 39 & 41 & 49 & 1 & $\mathrm{HV}$ \\
\hline 72 & $16 / 05 / 2013$ & $15: 40: 49$ & 37.846 & 16.237 & 28.88 & 2.9 & 14 & 1 & 30 & 45 & 70 & 314 & 2 & 217 & 76 & 2 & TF \\
\hline 73 & $18 / 05 / 2013$ & 20:12:07 & 37.107 & 15.040 & 6.71 & 1.9 & 10 & 0 & 225 & 80 & 50 & 345 & 24 & 98 & 41 & 2 & TS \\
\hline
\end{tabular}

Table 2. Focal mechanism parameters computed on 73 earthquakes shown in Figure 9. The Cat column indicates the type of mechanism (key: $\mathrm{TF}=$ thrust fault; $\mathrm{TS}=$ thrust-strike fault; NF = normal fault; NS = normal-strike fault; $\mathrm{SS}=$ strike slip; HV = horizontal-vertical kinematics).

Following a classic classification scheme [Frohlich, 1992] based on the plunge of T-, B-, and P-axes, we subdivided our solutions into five kinematic categories: thrust, thrust-strike, strike, normal, normal-strike, and horizontalvertical. These five categories are schematically represented in a ternary diagram (right bottom inset in Figure 9a) with different coded colours. The relocated hypocentres are projected onto the map and E-W and N-S sections of Figure 9a, with colours indicating the prevalent kinematics of the used classification scheme [Frohlich, 1992]. The map of distribution of focal mechanisms and the E-W and N-S sections (Figure 9a) show that earthquake kinematics are fairly homogeneous and in good agreement with a recently published regional structural model [Polonia et al., 2016]. Despite the presence of a few events having thrust and thrust-strike kinematics, most of the considered earthquakes have a prevalent normal, normal/oblique, and strike-slip kinematics. The few thrust and thrust-strike focal solutions may be associated with minor structures located near the coast of eastern Sicily [e.g. the Taormina faults; Alparone et al., 2018].

\section{Discussion}

The land network improved significantly from 2003 to 2012 throughout the Italian territory and, in particular, in Sicily. In this region, the increase in the number of seismic stations involved the areas of the Aeolian Islands, central Sicily and Mt. Etna (Figure 1). The earthquake detection capabilities improved significantly on land, such as a lowering of the magnitude of detectable earthquake was observed [Amato and Mele, 2008; Schorlemmer et al., 2010]. This is demonstrated by considering the significant improvement in event locations occurring on land; as an example, the decrease in the azimuthal gap for earthquake locations in the central Sicily area is shown. Two couples of events (Figure 2; Table 1), occurring in 2002 and 2012 and having similar locations, were characterized by a decrease in azimuthal gap from $264^{\circ}$ (28 October, 2002) to $88^{\circ}$ (18 July, 2012) and from $282^{\circ}$ (17 November, 2002) to $135^{\circ}$ (26 June, 2012) (Table 1). On the other hand, there having been no additional coverage in the Western Ionian Sea area, significant improvements in earthquake locations were not observed for events taking place offshore: the GAP remained substantially unchanged for couples of earthquakes 1-2, 3-4, and 5-6 (Figure 2; Table 1), all located with data recorded by the seafloor observatory, and their similar good quality is due to the use of NEMO-SN1 travel times in the location process. From this point of view, the NEMO-SN1 seafloor observatory proved to be the only station able to improve location for events occurring in the Ionian Sea. 
Tiziana Sgroi et al.
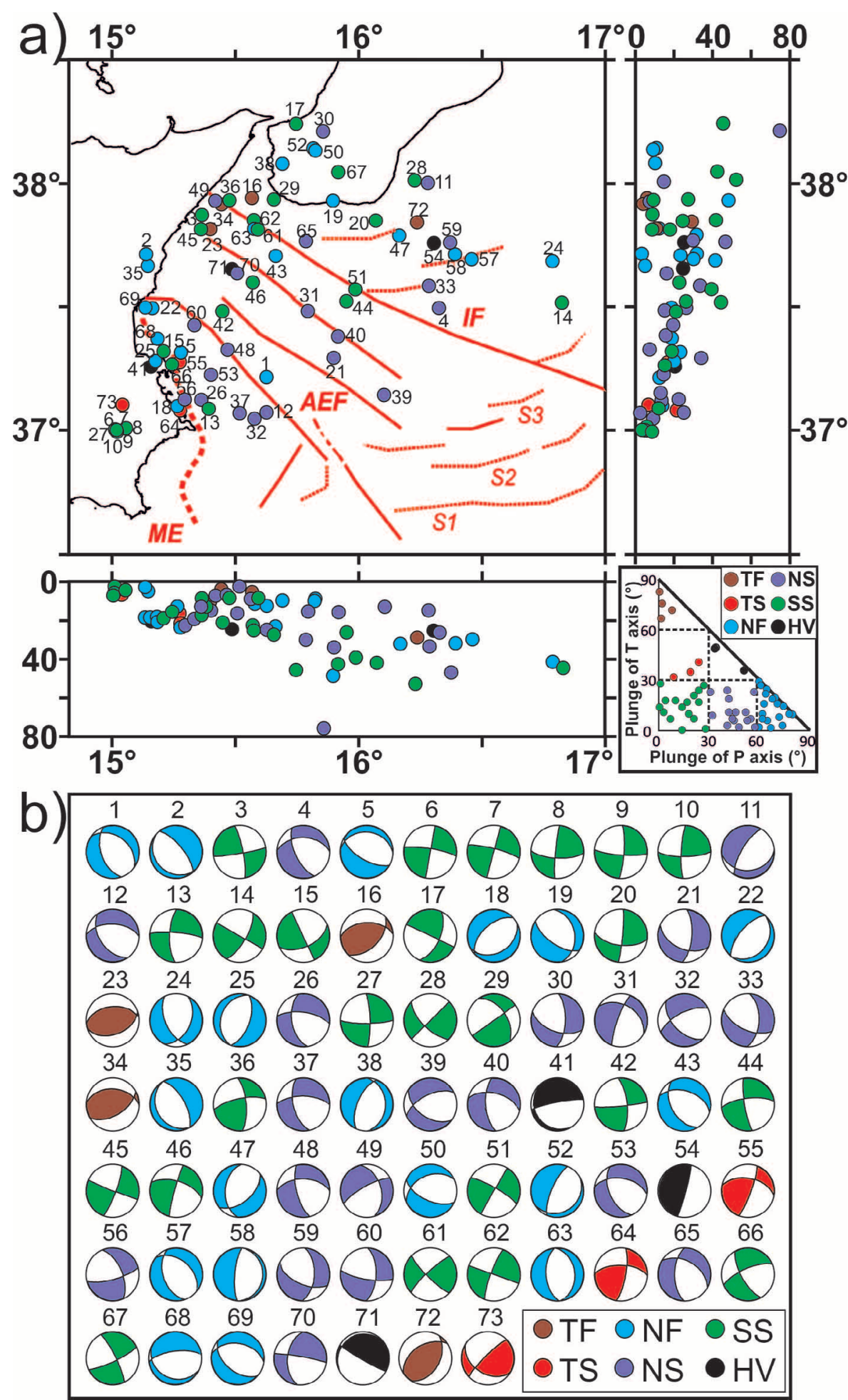

Figure 9. a) Map, E-W (bottom left) and N-S (upper right) sections of the 73 new focal mechanisms. The bottom right inset shows the classification scheme [Frohlich, 1992] based on the plunge of T-, B-, and P-axes of the 73 new focal solutions b). Key: TF, thrust fault; TS, thrust-strike fault; NF, normal fault; NS, normal-strike fault; SS, strike slip; HV, horizontal-vertical kinematics. Prevalent normal, normal-strike and strike-slip mechanisms characterize the Ionian Sea kinematics, with a few thrust kinematics concentrated in the offshore south of Messina Strait. 
During the two deployments of NEMO-SN1 (October 2002 - February 2003; June 2012 - May 2013), the improvement in earthquake locations occurring in the offshore is analysed by comparing locations performed with and without data recorded by NEMO-SN1 seafloor observatory. The combination of the arrival times from the single seafloor station and on land stations enhanced the accuracy of earthquake locations in terms of rms residuals, azimuthal gaps, and epicentre and hypocentre errors, as previously shown by Sgroi et al. [2006; 2007; 2012; 2021]. In this work, 1130 local earthquakes were relocated integrating the travel times from NEMO-SN1 and land stations. On 1130 earthquakes, 386 were recorded in the period 2002-2003, while 744 occurred in 2012-2013. On 358 earthquakes, 31 occurred in the Ionian Sea in the period 2002-2003 (most seismicity recorded during the first deployment of NEMO-SN1 was associated with the vigorous Mt. Etna eruption), while 327 took place in the period 2012-2013. We concentrated on these 358 earthquakes in the Ionian Sea and compared the results of locations performed with (Figure 4a) and without (Figure $4 \mathrm{~b}$ ) the seafloor observatory. The comparison of locations performed using the integrated network of seafloor observatory and land stations and with land stations only shows a reduction in terms of mean (M) computed on azimuthal gap, rms, horizontal and vertical errors, which highlights the high quality of locations with NEMO-SN1. Differences in the azimuthal GAP up to values of $143^{\circ}$ are computed $\left(\mathrm{M}=180^{\circ}\right.$ for locations with NEMO-SN1; $\mathrm{M}=199^{\circ}$ for locations without NEMO-SN1), while $\mathrm{M}$ computed on rms residuals shows similar values for locations with and without NEMO-SN1 ( $\mathrm{M}=0.30 \mathrm{~s}$ and $\mathrm{M}=0.27 \mathrm{~s}$, respectively). Moreover, a decrease in $\mathrm{M}$ computed on horizontal errors (from $\mathrm{M}=1.36 \mathrm{~km}$ computed on locations without NEMO-SN1 to $\mathrm{M}=0.70 \mathrm{~km}$ computed on locations with the seafloor station) and vertical errors (from $\mathrm{M}=2.82 \mathrm{~km}$ to $\mathrm{M}=1.24 \mathrm{~km}$ computed on locations without and with NEMO-SN1, respectively) is observed.

The recompilation of the local magnitude of the whole dataset was done to standardise the catalogue of the seismicity recorded in 2002-2003 and 2012-2013, and to highlight possible correlations among seismicity, the main tectonic structures in the Ionian Sea and the epicentres of the highest magnitude earthquakes occurring in the past. Although the maximum magnitude recorded during the study period was $\mathrm{M}_{\mathrm{L}}=4.5$, we noted that most events of our dataset took place near the same epicentre areas affected by the highest magnitude events which struck eastern Sicily and south Calabria in historical and recent times (red stars and years in Figures 4 and 8).

Figure 8a shows the epicentral map and the two cross-sections, including a total of 352 earthquakes in the Western Ionian Sea, with the use of data recorded by NEMO-SN1 and a 3D velocity model recently computed for the western Ionian area [Sgroi et al., 2021]. This seismicity is prevalently diffuse but some events are also clustered, as in the areas of onshore/offshore Hyblean and south Calabria. In the Ionian Sea, the seismicity is linked to the main active tectonic structures in this area, namely the external Calabrian Arc accretionary prism associated with the subduction process, the tectonic structures related to the Malta escarpment, and the seismogenic structures that are active in the Ionian Basin [Polonia et al., 2016; 2017]. The main tectonic feature of the crustal structures and uppermost mantle are also highlighted by the distribution of P-wave-travel time residuals (Figure 7). Residuals are largely controlled by the main crustal structures and show a significant variation in areal and depth distributions. The larger positive and negative values of residuals are 5-10 km depth interval where the contrast between high and low velocities are mainly associated with the tectonic structures and volcanism. Moreover, the IF is apparent in the depth interval between $5-15 \mathrm{~km}$ by the sudden transition from positive to negative residuals. This depth interval corresponds to the detachment of the Eastern Lobe of the subduction system on the top of the basement, which occurs at about $10 \mathrm{~km}$ depth [Polonia et al., 2016].

Although 1D and 3D locations (with NEMO-SN1 data) show similar epicentres, the main difference concerns the depths, demonstrating also the influence of a more realistic velocity model (tomographic model) in defining hypocentres more accurately. To quantify the difference between 3D locations performed with and without NEMOSN1, we computed the misfit of 352 earthquakes, taking into account the differences of latitude, longitude and depths for each event. Histograms of misfit (Figure 10a) show that 93\% of differences are within $10 \mathrm{~km}$, most events having misfits within $2 \mathrm{~km}$ (240 out 352, representing 66\% of the dataset; Figure 10b). In Figure 11, we mapped the values of misfits within $10 \mathrm{~km}$ computed on 352 events located with the 3D velocity model. We observe that more external locations are characterized by misfit over $5 \mathrm{~km}$ (from red to orange coloured) and this is justified by the locations of earthquakes since the combined land-marine network is not able to accurately capture the hypocentres for events occurring in these areas. On the other hand, differences are clearly visible in the central part of the study area, where earthquakes are better located by the combined land-marine network. Moreover, using the same velocity model for the 3D location performed with and without NEMO-SN1, it is presumable that differences in latitude, longitude and depth (that are more consistent) are imputable to the seafloor station travel times. Indeed, the most 


\section{Tiziana Sgroi et al.}

relevant differences are observed in the central part of the Ionian basin, while minor differences are observable near the coast where land stations assure a good coverage around hypocentres. This fact also confirms that the increasing seismic stations coverage has not influence in the location of events occurring offshore, where NEMOSN1 continued to be the foremost tool in the location process. In the onshore, an area characterized by high value of shift is visible in the Hyblean Plateau and can be associated with the dike intrusions in a Neogene-Quaternary volcanic area [Behncke, 2004]; P-wave travel time residuals also highlight the presence of lower velocities in this area (depth interval 0-5 km in Figure 7). In the offshore, remarkable similarities are found between the main shifts of locations performed with and without NEMO-SN1 and the positions of serpentinite diapirs derived by MultiChannel Seismic (MCS) data only and MCS and magnetic/sediment core data [Polonia et al., 2017], as well as with free-air satellite-derived gravity data [Polonia et al., 2011]. The same shifts can also be associated with the major structural boundaries and domains of the Calabrian Arc subduction complex. The pattern of misfit and the distribution of depths correlate well with the arc-orthogonal extension across the subduction zone [Sgroi et al., 2021], whereas some uncertainties can be related to the low resolution of seismic data in the offshore. The arcorthogonal extension is also clearly apparent in the map of residuals at 15-20 km (Figure 7), whose lower limit coincides with the transition from continental to oceanic crust [Dannowski et al., 2019].

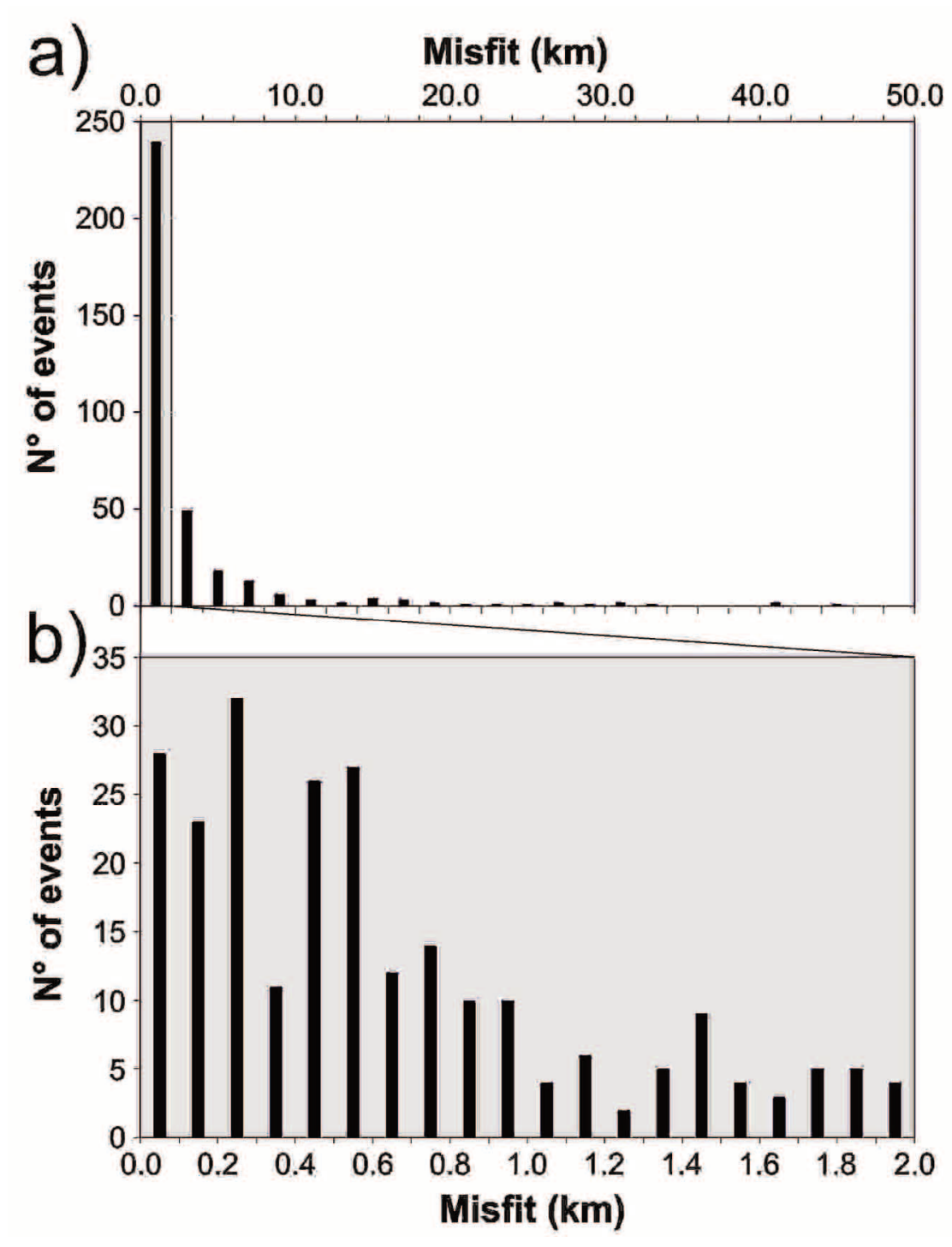

Figure 10. a) Differences in latitude, longitude and depth (misfit) of 3D locations performed with and without data from NEMO-SN1; about $93 \%$ of these differences are within $10 \mathrm{~km}$. b) Misfit of differences distribution within $2 \mathrm{~km}$; about $66 \%$ of the events are characterised by misfit values minor to $2 \mathrm{~km}$. 
Significant features are also evident in the four cross-sections traced on 3D relocations and shown in Figure $11 \mathrm{~b}$, where seismicity is projected along the traces shown in Figure 11a, having a width of $\pm 10 \mathrm{~km}$ from the cross section line. From sections A-A' and B-B' in Figure 11, an area extending from the surface to more than $10 \mathrm{~km}$ having scarce seismic activity, is visible along the Alfeo-Etna Fault (AEF) that shows an aseismic behaviour in the accretionary wedge, probably linked to changes in rheology within the subduction complex [Sgroi et al., 2021]. The cross-sections C-C' and D-D' show a crustal thickening (crustal thickness about $30 \mathrm{~km}$ ) associated with the seismic clusters, which occur near the coast of eastern Sicily, south Calabria and along the IF system, whereas in the central part of basin, crustal thickness is on average about $20 \mathrm{~km}$, compatible with an oceanic crust [Dannowski et al., 2019]. In general, the distribution of 352 earthquakes recorded by NEMO-SN1 along the four cross sections reflects the presence of an arc-shaped area connecting AEF and IF near the eastern coast of Sicily at different depths. The shape and position of this area (characterized by low $\mathrm{V}_{\mathrm{P}}$, visible in the $15-20 \mathrm{~km}$ depth interval of Figure 7) are consistent with the distribution of the depth misfit shown in Figure 11 and this area corresponds to the arc-normal incipient rifting across the Calabrian subduction zone [Sgroi et al., 2021].

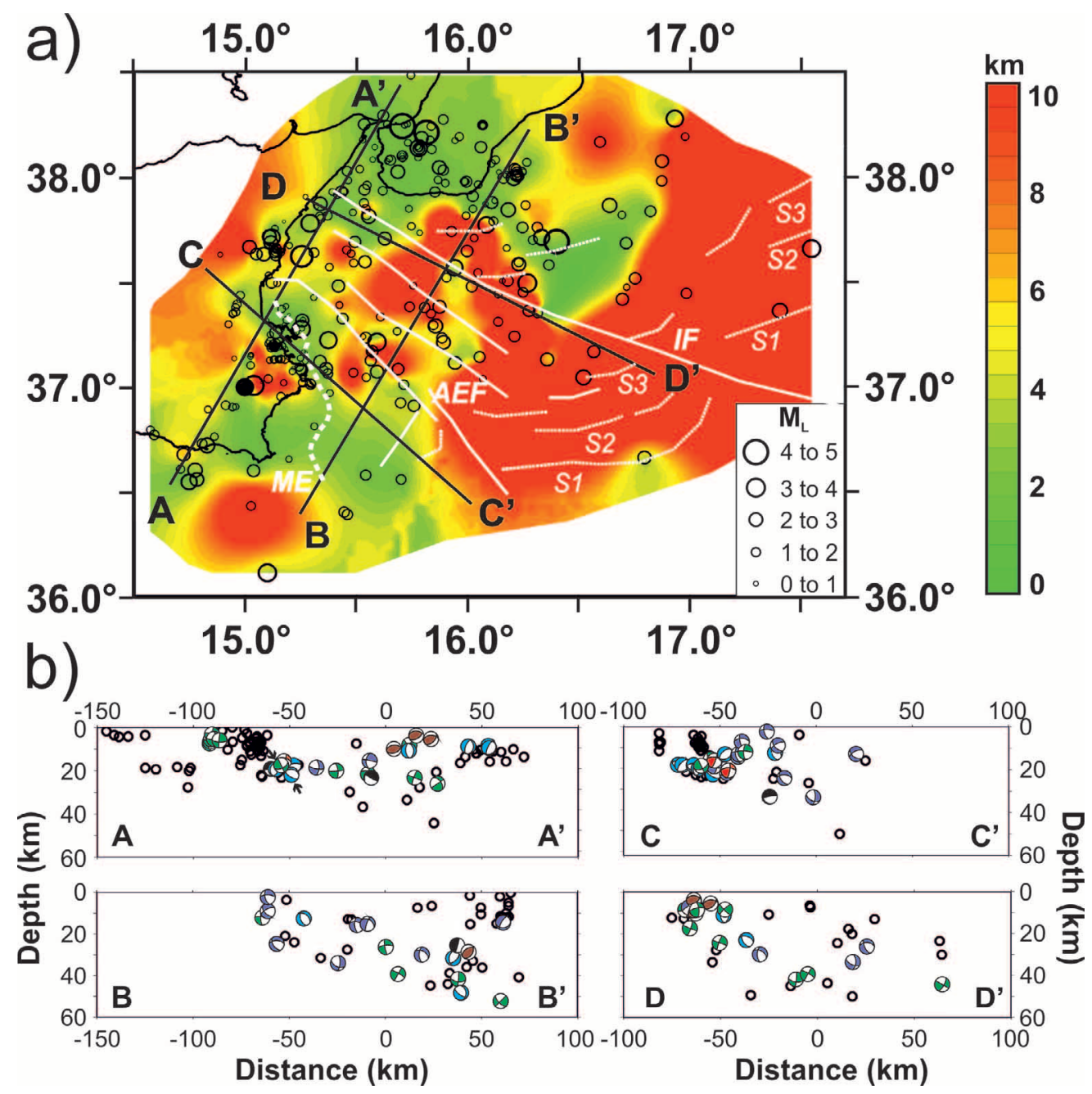

Figure 11. a) Map of misfit in terms of differences in latitude, longitude and depth between 3D locations performed with and without NEMO-SN1 (up to values of $10 \mathrm{~km}$ ). The areas from red to orange correspond to structural heterogeneities found in the Western Ionian Sea and near the coast. b) Cross-sectional view of the relocations from the 3D model. Seismicity is projected along the traces shown in a), having width of $\pm 10 \mathrm{~km}$ from the crosssection line. Focal mechanisms for events along the sections are shown. Black arrows refer to the earthquakes having locations and mechanisms similar to those of the main shock and aftershock of the 1990 earthquake. 


\section{Tiziana Sgroi et al.}

The distribution of seismicity and map of focal mechanisms show the coexistence of two main tectonic regimes (strike-slip and extensional domains), while a compressive tectonic is relegated to rather small areas, as in the Taormina offshore. The presence of only one subduction-type earthquake in the frontal thrust of Calabrian Arc subduction system confirms that the subduction may be considered blocked or inactive, although it is evident in the deepening of the seismogenic layer in offshore south Calabria [Sgroi et al., 2021].

Two new focal mechanisms in our dataset are computed for earthquakes occurring near the epicentre area of the 1990 earthquake (events 5 and 15 in Table 2). The solutions of these events are similar to the focal mechanisms that were computed in other works for the main shock and aftershock of the 1990 earthquake. Giardini et al. [1995] and Sgroi et al. [2021] computed a normal kinematic for the main shock of the 1990 earthquake and these solutions are very similar to that computed on the event 5 (Table 2) of our work. On the other hand, a strike-slip mechanism is computed for event 15 (Table 2) and it is similar to that computed by Amato et al. [1995] on the largest aftershock of the 1990 sequence. These results confirm that distinctive structures were activated during the 1990 sequence and that these seismogenic structures are still active and potentially dangerous.

\section{Conclusions}

The location, the extension and the seismic potential of faults located in the Ionian Sea are poorly constrained based only on data recorded by land seismic networks. The NEMO-SN1 seafloor observatory deployed in the Western Ionian Sea has proved a promising tool in detecting local seismicity and highlighting the seismogenic structures in this area, contributing to depict the geological and structural features offshore and in the coastal areas of eastern Sicily.

The quality of locations (from low-medium to medium-high magnitude) of earthquakes occurring offshore has been enhanced by the use of the marine station. We demonstrated that the use of the combined network of land stations and the single seafloor station NEMO-SN1 has improved earthquake locations in terms of azimuthal GAP and horizontal and vertical errors. Moreover, the differences in latitude, longitude and depth between the 1D and 3D locations, shows that the major shifts are concentrated in correspondence of geological and tectonic structures extending either on land and offshore, with the main differences in the hypocentre depths. Independent analysis performed on P-wave travel time residuals confirms our findings. This proves that seafloor observatory data are very important to better constrain earthquake locations and to detect the position of structural offshore heterogeneities.

The handpicking of the seismic phases performed on NEMO-SN1 seismograms, allowed us to collect P-wave first motion polarities, and 73 new focal mechanisms were computed. These focal mechanisms contributed in highlighting the kinematics of the area, delineating prevalent normal, normal/oblique, and strike-slip solutions. These solutions are in good agreement with the regional structural model, while the few thrust and thrust-strike focal solutions may be associated with minor structures near the coast of eastern Sicily. Similarities of locations and fault plain solutions are found between a few events of our dataset and the main shock and aftershock of the 1990 earthquake, demonstrating that the seismogenic potential of this area, which experienced large earthquakes in the past, has not diminished.

Moreover, the seismicity that is potentially missed by land seismic stations can be recorded and precisely located by using marine stations. This testifies to the importance of extending the network to the sea in a permanent way.

Acknowledgments. We wish to thank Paolo Favali for his helpful comments and suggestions and Stephen Conway for revising the English form of the manuscript. We also wish to acknowledge the Sector Editor Barbara Orecchio and the insightful and constructive reviews of two anonymous reviewers.

\section{References}

Alparone, S., G. Barberi, T. Sgroi and A. Ursino (2018). A seismological and kinematic study of Taormina Fault (Eastern Sicily, Italy). The $36^{\text {th }}$ General Assembly of the European Seismological Commission, Valletta Malta, 2 - 7 September 2018, Abstract ESC2018-S4-724.

Amato, A., R. Azzara, A. Basili, C. Chiarabba, M. Cocco, M. Di Bona, and G. Selvaggi (1995). Main shock and 
aftershocks of the December, 13, 1990, Eastern Sicily earthquake, Annali di Goefisica, XXXVIII, 2, 255-266.

Amato, A. and F.M. Mele (2008). Performance of the INGV National Seismic Network from 1997 to 2007. Ann. Geophys., 51, 2-3, 417-431, https://doi.org/10.4401/ag-4454.

Argnani, A. (2009). Evolution of the southern Tyrrhenian slab tear and active tectonics along the western edge of the Tyrrhenian subducted slab, Geological Society Special Publication, 311, 193-212, http://dx.doi.org/10.1144/SP311.7.

Barberi, G., O, Cocina, V. Maiolino, C. Musumeci, and E. Privitera (2004). Insight into Mt. Etna (Italy) kinematics during the 2002-2003 eruption as inferred from seismic stress and strain tensors, Geophys. Res. Lett., 31, L21614, https://doi.org/10.1029/2004GL020918.

Barberi, G., L. Beranzoli, P. Favali, G. Neri, and T. Sgroi (2006). Seismic location improvements from an OBS/H temporary network in Southern Tyrrhenian Sea, Ann. Geophys., 49, 2/3, 739-749.

Ben-Avraham, Z., V. Lyakhovsky and M. Grasso (1995). Simulation of collision zone segmentation in the central Mediterranean, Tectonophysics 243, 57-68, http://dx.doi.org/10.1016/0040-1951(94)00191-B.

Behncke, B. (2004). Late Pliocene volcanic island growth and flood basalt-like lavaemplacement in the Hyblean Mountains (SE Sicily), J. Geophys. Res., 109, B09201, doi:10.1029/2003JB002937.

Bianca, M., C. Monaco, L. Tortorici and L. Cernobori (1999). Quaternary normal faulting in south-eastern Sicily (Italy): a seismic source for the 1693 large earthquake, Geophys. J. Int., 139, 370-394, https://doi.org/10.1046/j.1365-246x.1999.00942.x.

Billi, A., L. Minelli, B. Orecchio and D. Presti (2010). Constraints to the cause of three historical tsunamis (1908, 1783, and 1693) in the Messina Straits region, Sicily, southern Italy, Seism. Res. Lett., 81, 907-915, https://doi.org/10.1785/gssrl.81.6.907.

Billi, A., M. Cuffaro, L. Beranzoli, S. Bigi, A. Bosman, C. Caruso, A. Conti, A. Corbo, A. Costanza, G. D’Anna, M. De Caro, C. Doglioni, D. Embriaco, G. Fertitta, F. Frugoni, L. Gasperini, F. Italiano, G. Lazzaro, M. Ligi, E. Martorelli, S. Monna, C. Montuori, A. Nigrelli, G. Passafiume, L. Petracchini, P. Petricca, A. Polonia, G. Proietti, L. Ruggiero, T. Sgroi and M.C. Tartarello (2020). The SEISMOFAULTS Project: first surveys and preliminary results for the Ionian Sea area, southern Italy, Ann. Geophys, 63, 3, doi:10.4401/ag-8171.

Boschi, E., E. Guidoboni, G. Ferrari, G. Valensise and P. Gasperini (1997). Catalogue of the strong earthquakes in Italy from $461 \mathrm{BC}$ to 1990. ING. \& SGA, Bologna, 973.

Castello, B., G. Selvaggi, C. Chiarabba and A. Amato (2006). CSI Catalogo della sismicità italiana 1981-2002. Versione 1.1 (INGV-CNT, Roma).

Coltelli, M. D. Cavallaro, M. Firetto Carlino, L. Cocchi, F. Muccini, A. D’Alessandro, M.E. Claude, C. Monaco, J.M. Ibáñez, F. Zgur, D. Patanè, C. Carmisciano, G. D’Anna, M.T. Pedrosa Gonzales, T. Teixidó, R. D’Anna, G. Fertitta, G. Passafiume, S. Speciale, F. Grassa, A.P. Karageorgis, L. Sormani, L. Facchin, G. Visnovic, D. Cotterle, R. Blanos, P. Mansutti, A. Sulli, F. Cultrera, F. Carrión and S. Rapisarda (2016). The marine activities performed within the TOMO-ETNA experiment., Ann. Geophys., 59, 4, S0428, https://doi.org/10.4401/ag-7081.

Dahm, T., M. Thorwart, E.R. Flueh, T. Braun, H. Herber, P. Favali, L. Beranzoli, G. D’Anna, F. Frugoni, and G. Smriglio (2002). Ocean Bottom Seismometers deployed in Tyrrhenian Sea, EOS, Trans. AGU, 83, 29:309-315.

Dannowski, A., H. Kopp, F. Klingelhoefer, D. Klaeschen, M.A. Gutscher, A. Krabbenhoeft, D. Dellong, M. Rovere, D. Graindorge, C. Papenberg, and I. Klaucke (2019). Ionian abyssal plain: A window into the Tethys oceanic lithosphere. Ionian Abyssal Plain: a window into the Tethys oceanic lithosphere, Solid Earth, 10, 447462, https://doi.org/10.5194/se-10-447-2019 (2019).

Doglioni, C., F. Innocenti and G. Mariotti (2001). Why Mt.Etna?, Terra Nova, 13, 25-31.

Favali, P. and L. Beranzoli (2006). Seafloor Observatory Science: a review, Ann. Geophys., 49(2/3), 515-567, https://doi.org/10.4401/ag-3125.

Favali, P., L. Beranzoli, G. D’Anna, F. Gasparoni, and H.W. Gerber (2006). NEMO-SN1 The 1st "Real-Time” Seafloor Observatory of ESONET, Nuclear Instruments and Methods in Physics Research Section A: Accelerators, Spectrometers, Detectors and Associated Equipment, 567, 2, 462-467, doi:10.1016/j.nima.2006.05.255.

Favali, P., and L. Beranzoli (2009). EMSO: European Multidisciplinary Seafloor Observatory, Nuclear Instruments and Methods in Physics Research Section A: Accelerators, Spectrometers, Detectors and Associated Equipment, 602, 21-27, doi:10.1016/j.nima.2008.12.214.

Favali, P., R. Person, C.R. Barnes, Y. Kaneda, J.R. Delaney, and S.-K. Hsu (2010). Seafloor Observatory Science. In: J. Hall, D.E. Harrison, D. Stammer (eds.), Proceedings of the OceanObs'09: Sustained Ocean. Observations and 


\section{Tiziana Sgroi et al.}

Information for Society conference 2, Venice, Italy, 21-25 September 2009, ESA Publication WPP-306 ISSN:1609-042X, doi:10.5270/OceanObs09.cwp28.

Favali, P., F. Chierici, G. Marinaro, G. Giovanetti, A. Azzarone, L. Beranzoli, A. De Santis, D. Embriaco, S. Monna, N. Lo Bue, T. Sgroi, G. Cianchini, L. Badiali, E. Qamili, M. De Caro, G. Falcone, C. Montuori, F. Frugoni, G. Riccobene, M. Sedita, G. Barbagallo, G. Cacopardo, C. Calì, R. Cocimano, R. Coniglione, M. Costa, A. D’Amico, F. Del Tevere, C. Distefano, F. Ferrera, V. Giordano, M. Imbesi, D. Lattuada, E. Migneco, M. Musumeci, A. Orlando, R. Papaleo, P. Piattelli, G. Raia, A. Rovelli, P. Sapienza, F. Speziale, A. Trovato, S. Viola, F. Ameli, M. Bonori, A. Capone, R. Masullo, F. Simeone, L. Pignagnoli, N. Zitellini, F. Bruni, F. Gasparoni, and G. Pavan (2013). NEMO-SN1 abyssal cabled observatory in the Western Ionian Sea, IEEE J. Ocean. Eng., 38, 358-374, https://doi.org/10.1109/JOE.2012.2224536.

Favali, P., L. Beranzoli, and A. De Santis (eds.) (2015). Seafloor Observatories: A New Vision of the Earth from the Abyss, Springer-Praxis books in Geophysical Sciences, Springer-Verlag Berlin Heidelberg, ISBN 978-3-64211373-4, e-ISBN 978-3-642-11374-1, doi:10.1007/978-3-642-11374-1, 676.

Frohlich, C. (1992). Triangle diagrams: ternary graphs to display similarity and diversity of earthquake focal mechanisms, Phys. Earth Planet. Int., 75, 193-198.

Giardini, D., B. Palombo and N.A. Pino (1995). Long-period modelling of MedNet waveforms for the December 13, 1990 Eastern Sicily earthquake, Annali di Geofisica, XXXVIII, 2, 267-282.

Goslin, J., N. Lourenço, R.P. Dziak, R. Del Wayne Bohnenstiehl, J. Haxel and J. Luis (2005). Long-term seismicity of the Reykjanes Ridge (North Atlantic) recorded by a regional hydrophone array, Geophys. J. Int., 162, 516-524.

Gruppo Analisi Dati Sismici (2019). Catalogo dei terremoti della Sicilia Orientale - Calabria Meridionale (19992019). INGV, Catania, http://sismoweb.ct.ingv.it/maps/eq_maps/sicily/catalogue.php.

Gutscher, M.-A., S. Dominguez, B. Mercier de Lepinay, L. Pinheiro, F. Gallais, N. Babonneau, A. Cattaneo, Y. LeFaou, G. Barreca, A. Micallef and M. Rovere (2016). Tectonic expression of an active slab tear from high-resolution seismic and bathymetric data offshore Sicily (Ionian Sea), Tectonics, 35, 39-54.

Hino, R., T. Kanazawa and A. Hasegawa (1996). Interplate seismic activity near the northern Japan Trench deduced from ocean bottom and landbased seismic observations, Phys. Earth Planet. Int., 93, 37-52.

Hirn, A., A. Nercessian, M. Sapin, F. Ferrucci and G. Wrrtlinger (1991). Seismic heterogeneity of Mt. Etna: structure and activity, Geophys. J. Int., 105, 139-153.

Hirn, A., R. Nicolich, J. Gallart, M. Laigle, L. Cernobori and ETNASEIS Scientific Group (1997). Roots of Etna volcano in faults of great earthquakes, Earth Planet. Sci. Lett., 148, 171-191, http://dx.doi.org/10.1016/ S0012$821 \mathrm{X}(97) 00023-\mathrm{X}$.

INGV Seismological Data Centre (2006). Rete Sismica Nazionale (RSN). Istituto Nazionale di Geofisica e Vulcanologia (INGV), Italy, https://doi.org/10.13127/SD/X0FXNH7QFY.

ISIDe Working Group (2007). Italian Seismological Instrumental and Parametric Database (ISIDe). Istituto Nazionale di Geofisica e Vulcanologia (INGV), https://doi.org/10.13127/ISIDE.

Lahr, J.C. (1989). HYPOELLIPSE/version 2.0: a computer program for determining local earthquake hypocentral parameters, magnitude, and first motion pattern, Open-File Report - U. S. Geological Survey, 95, 89-116.

Langer, H., R. Raffaele, A. Scaltrito and L. Scarfi (2007). Estimation of an optimum velocity model in the CalabroPeloritan mountains - assessment of the variance of model parameters and variability of earthquake locations, Geophys. J. Int., 170, 1151-1164, https://doi.org/10.1111/j.1365-246X.2007.03459.x.

Lawton, J., C. Frohlich, H. Pulpan and G.V. Latham (1982). Earthquake activity at the Kodiak continental shelf, Alaska, determined by land and ocean bottom seismograph networks, Bull. Seism. Soc. Am., 72, 207-220.

Meletti, C., E. Patacca and P. Scandone (2000). Construction of a seismotectonic model: The case of Italy, Pure Appl. Geophys., 157, 11-35, http://dx.doi.org/10.1007/PL00001089. Monna, S., T. Sgroi and T. Dahm (2013). New insights on volcanic and tectonic structures of the southern Tyrrhenian (Italy) from marine and land seismic data, Geochem. Geophys. Geosys., 14, 9, https://doi.org/10.1002/ggge.20227.

Musumeci, C., G. Di Grazia and S. Gresta (2003). Minimum 1-D velocity model in Southeastern Sicily (Italy) from local earthquake data: an improvement in location accuracy, J. Seismol., 7, 469-478, https://doi.org/10.1023/B:JOSE.0000005716.42446.da.

Patanè, D. (2002). Aggiornamento delle attività di monitoraggio sismico all'Etna, http://www.ct.ingv.it/report/Rapporto_eruzione20021030.pdf.

Polonia, A., L. Torelli, P. Mussoni, L. Gasperini, A. Artoni and D. Klaeschen (2011). The Calabrian Arc subduction 
complex in the Ionian Sea: regional architecture, active deformation, and seismic hazard, Tectonics, 30, TC5018, http://doi.org/10.1029/2010TC002821.

Polonia, A., G. Panieri, L. Gasperini, G. Gasparotto, L. G. Bellucci and L. Torelli (2013). Turbidite paleoseismology in the Calabrian Arc Subduction Complex (Ionian Sea), Geochem. Geophys. Geosys., 14, 1, https://doi.org/10.1029/2012GC004402.

Polonia, A., L. Torelli, A. Artoni, M. Carlini, C. Faccenna, L. Ferranti, L. Gasperini, R. Govers, D. Klaeschen, C. Monaco, G. Neri, N. Nijholt, B. Orecchio and R. Wortel (2016). The Ionian and Alfeo-Etna fault zones: New segments of an evolving plate boundary in the central Mediterranean Sea?, Tectonophysics, 675, 69-90, https://doi.org/10.1016/j.tecto.2016.03.016.

Polonia, A., L. Torelli, L. Gasperini, L. Cocchi, F. Muccini, E. Bonatti, C. Hensen, M. Schmidt, S. Romano, A. Artoni and M. Carlini (2017). Lower plate serpentinite diapirism in the Calabrian Arc subduction complex, Nature Communications, doi:10.1038/s41467-017-02273-x.

Reasenberg, P. and D. Oppenheimer (1985). FPFIT, FPPLOT and FPPAGE: FORTRAN computer programs for calculating and displaying earthquake fault-plane solutions, U.S. Geol. Surv., Open File Rep., 85-739.

Scandone, P., E. Patacca, R. Radoicic, W.B.F. Ryan, M.B. Cita, M. Rawson, H. Chezar, E. Miller, J. McKenzie and S. Rossi (1981). Mesozoic and Cenozoic rocks from the Malta Escarpment (central Mediterranean), Bull. Am. Ass. Petroleum Geologist, 65, 1,299-1,319.

Schorlemmer, D., F.M. Mele and W. Marzocchi (2010). A completeness analysis of the National Seismic Network of Italy, J. Geophys. Res., 115, B04308, https://doi.org/10.1029/2008JB006097.

Sgroi, T., T. Braun, T. Dahm and F. Frugoni (2006). An improved seismicity picture of the Southern Tyrrhenian area by the use of OBS and land-based network: the TYDE experiment, Ann. Geophys., 49, 2/3, 801-817.

Sgroi, T., L. Beranzoli, G. Di Grazia, A. Ursino and P. Favali (2007). New observations of local seismicity by the SN-1 seafloor observatory in the Ionian Sea, off-shore eastern Sicily (Italy), Geophys. J. Int., 169, 490-501, https://doi.org/10.1111/j.1365-246X.2007.03348.x.

Sgroi, T., R. De Nardis and G. Lavecchia (2012). Crustal structure and seismotectonics of central Sicily (Southern Italy): new constraints from instrumental seismicity, Geophys. J. Int., 189, 3, 1237-1252, http://doi.org/ 10.1111/j.1365-246X.2012.05392.x.

Sgroi, T., S. Monna, D. Embriaco, G. Giovanetti, G. Marinaro, and P. Favali (2014). Geo-hazards in the Western Ionian Sea: insights from non-earthquake signals recorded by the NEMO-SN1 seafloor observatory, Oceanography, 27, 2, 154-166, http://doi.org/10.5670/oceanog.2014.51.

Sgroi, T., G. Di Grazia and P. Favali (2019). Volcanic Tremor of Mt. Etna (Italy) Recorded by NEMO-SN1 Seafloor Observatory: A New Perspective on Volcanic Eruptions Monitoring, Geosciences, 2019, 9, 115, doi:10.3390/geosciences9030115.

Sgroi, T., A. Polonia, G. Barberi, A. Billi and L. Gasperini (2021). New seismological data from the Calabrian Arc reveal arc-orthogonal extension across the subduction zone, Scientific Reports, 11, 473, https://doi.org/10.1038/s41598-020-79719-8.

Shinohara, M., K. Suyehiro and T. Murayama (2003). Microearthquake seismicity in relation to double convergence around the Solomon Islands arc by ocean-bottom seismometer observation, Geophys. J. Int., 153, 691- 698.

Tilmann, F., E. Flueh, L. Planert, T. Reston and W. Weinrebe (2004). Microearthquake seismicity of the Mid-Atlantic Ridge at $5^{\circ}$ S: a view of tectonic extension, J. Geophys. Res., 109, doi:10.1029/2003JB002827.

Tinti, S., A. Maramai and L. Graziani (2004). The new catalogue of Italian tsunamis, Nat. Hazards, 33, 439-465, http://dx.doi.org/10.1023/B:NHAZ.0000048469.51059.65.

Tréhu, A.M., W.S.D. Wilcock, R. Hilmo, P. Bodin, J. Connolly, E.C. Roland and J. Braunmiller (2018). The role of the Ocean Observatories Initiative in monitoring the offshore earthquake activity of the Cascadia subduction zone, Oceanography, 2018, 31, 104-113.

Zhang, H., C. Thurber and P. Bedrosian (2009). Joint inversion for Vp, Vs, and Vp/Vs at SAFOD, Parkfield, California Geochem. Geophys. Geosys., 10, 11, http://doi.org/10.1029/2009GC002709.

Wilcock, W.S.D., M. Tolstoy, F. Waldhauser, C. Garcia, Y.J. Tan, D.R. Bohnenstiehl, J. Caplan-Auerbach, R.P. Dziak, A.F. Arnulf and M. Everett Mann (2016). Seismic constraints on caldera dynamics from the 2015 Axial Seamount eruption, Science, 354, 6318, doi:10.1126/science.aah5563. 
Tiziana Sgroi et al.

*CORRESPONDING AUTHOR: Tiziana SGROI,

Istituto Nazionale di Geofisica e Vulcanologia, Roma, Italy, e-mail: tiziana.sgroi@ingv.it (c) 2021 the Author(s). All rights reserved. Open Access. This article is licensed under a Creative Commons Attribution 3.0 International 